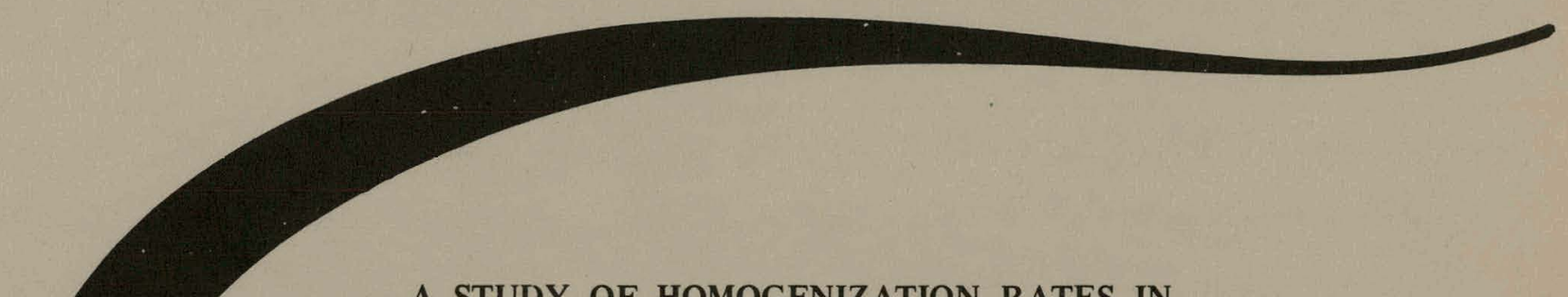

A STUDY OF HOMOGENIZATION RATES IN

PLUTONIUM-1 WEIGHT PERCENT GALLIUM ALLOY

AS A FUNCTION OF

PERCENT REDUCTION BY COLD ROLLING

R. Jack Erfurdt

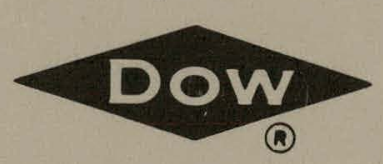

DOW CHEMICAL U.S.A. ROCKY FLATS DIVISION

P. O. BOX 888

GOLDEN, COLORADO 80401

U. S. ATOMIC ENERGY COMMISSION CONTRACT AT(29-1)-1106 


\section{DISCLAIMER}

This report was prepared as an account of work sponsored by an agency of the United States Government. Neither the United States Government nor any agency Thereof, nor any of their employees, makes any warranty, express or implied, or assumes any legal liability or responsibility for the accuracy, completeness, or usefulness of any information, apparatus, product, or process disclosed, or represents that its use would not infringe privately owned rights. Reference herein to any specific commercial product, process, or service by trade name, trademark, manufacturer, or otherwise does not necessarily constitute or imply its endorsement, recommendation, or favoring by the United States Government or any agency thereof. The views and opinions of authors expressed herein do not necessarily state or reflect those of the United States Government or any agency thereof. 


\section{DISCLAIMER}

Portions of this document may be illegible in electronic image products. Images are produced from the best available original document. 


\section{LEGAL NOTICE}

This report was prepared as an account of work sponsored by the United States Government. Neither the United States nor the United States Atomic Energy Commission, nor any of their employees, nor any of their contractors, subcontractors, or their employees, makes any warranty, expressed or implied, or assumes any legal liability or responsibility for the accuracy, completeness or usefulness of any information, apparatus, product or process disclosed, or represents that its use would not infringe privately owned rights.

Printed in the United States of America

Available from the

National Technical Information Service

U. S. Department of Commerce

Springfield, Virginia 22151

Price: Printed Copy $\$ 4.00$ Microfiche $\$ 1.45$ 


\title{
A STUDY OF HOMOGENIZATION RATES IN PLUTONIUM-1 WEIGHT PERCENT GALLIUM ALLOY AS A FUNCTION OF PERCENT REDUCTION BY COLD ROLLING
}

\author{
R. Jack Erfurdt
}

Research and Development

PLUTONIUM METALLURGY

\section{SUBJECT DESCRIPTORS}

Plutonium

Homogenization

Gallium Alloys

Rolling

DOW CHEMICAL U.S.A.

ROCKY FLATS DIVISION

P. O. BOX 888

GOLDEN, COLORADO 80401
NOIICE

This report was prepared as an account of work sponsored by the United States Government. Neither the United States nor the United States Atomic Energy Commission, nor any of their employees, nor any of their contractors, subcontractors, or their employees, makes any warranty, express or implied, or assumes any legal liability or responsibility for the accuracy, completeness or usefulness of any information, apparatus, product or process disciosed, or represents that its use would not infringe privately owned rights.

Prepared under Contract AT(29-1)-1106

for the

Albuquerque Operations Office

U. S. Atomic Energy Commission 
RFP-2235 


\section{CONTENTS}

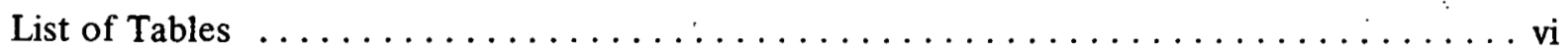

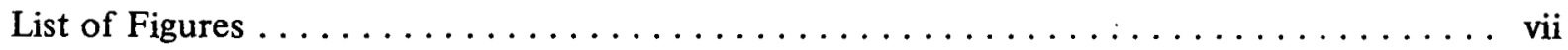

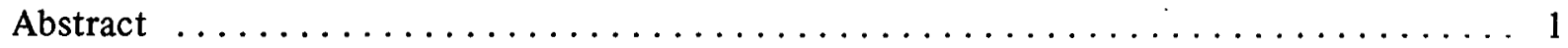

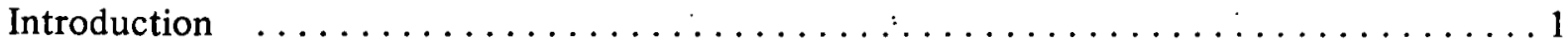

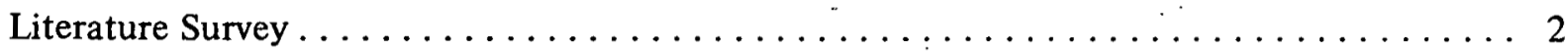

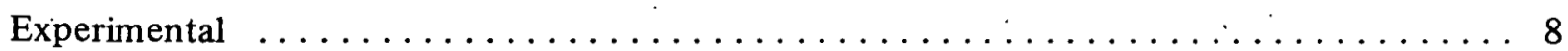

Experimental Program $\ldots \ldots \ldots \ldots \ldots \ldots \ldots \ldots \ldots \ldots \ldots \ldots \ldots, 8$

Experimental Procedures $\ldots \ldots \ldots \ldots \ldots \ldots \ldots \ldots \ldots \ldots \ldots \ldots$

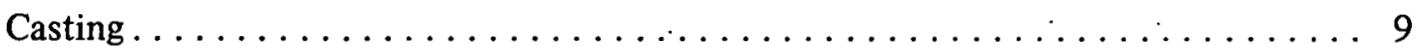

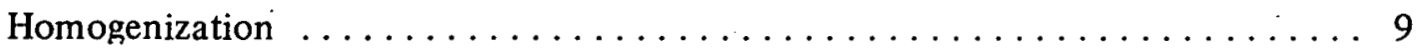

Metallography $\ldots \ldots \ldots \ldots \ldots \ldots \ldots \ldots \ldots \ldots \ldots \ldots \ldots \ldots \ldots \ldots \ldots$

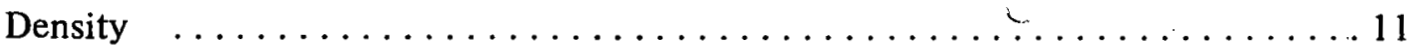

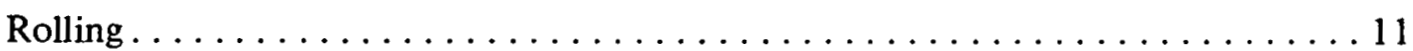

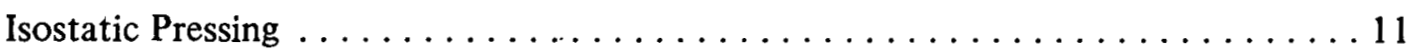

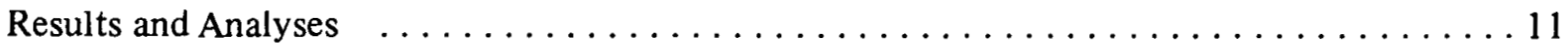

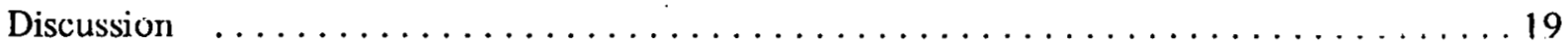

Predictions of Homogenizing Times for As-Cast Samples . . . . . . . . . . . . . 19

Diffusion Models ................................ 19

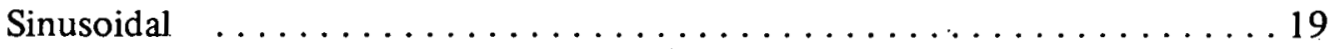

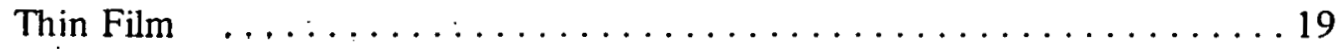

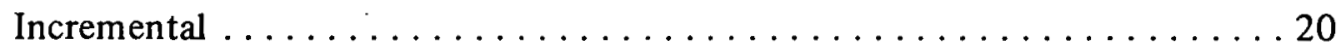




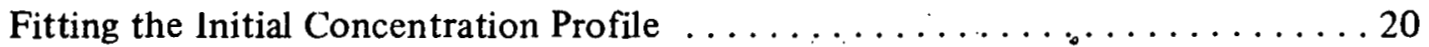

Comparing Theoretical and Actual Homogenization $\ldots \ldots \ldots \ldots \ldots \ldots$

Predictions of Homogenization Times for Rolled Samples $\ldots \ldots \ldots \ldots \ldots \ldots \ldots 22$

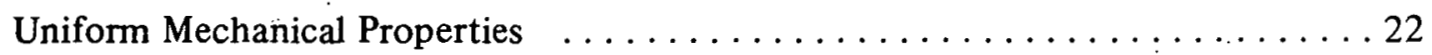

Nonuniform Mechanical Properties $\ldots \ldots \ldots \ldots \ldots \ldots \ldots \ldots \ldots \ldots \ldots \ldots \ldots \ldots$

Deformation of the High Gallium Region $\ldots \ldots \ldots \ldots \ldots \ldots \ldots \ldots$

Deformation of the Low Gallium Region $\quad \ldots \ldots \ldots \ldots \ldots \ldots \ldots$

Deformation of the Cored Pu-1 Wt $\%$ Ga Alloy Grains $\ldots \ldots \ldots 23$

Comparing Theoretical and Actual Homogenization $\ldots \ldots \ldots \ldots \ldots \ldots \ldots$

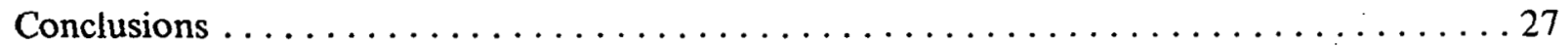

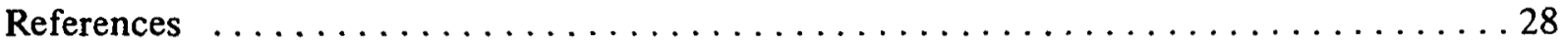




\section{T A B L E S}

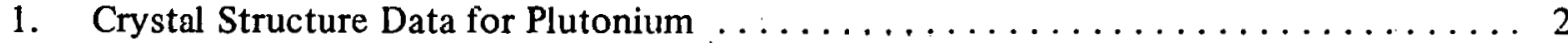

2. Nominal Impurities of Plutonium Used for Study $\ldots \ldots \ldots \ldots \ldots \ldots \ldots \ldots \ldots \ldots$

3. As-Rolled and Isostatically Pressed Density Versus Percent Rolling Reduction $\ldots \ldots 15$

4. Mechanical Properties of Unalloyed and Gallium Alloyed Plutonium . . . . . . . . 24 


\section{F I G U R E S}

1. Idealized Temperature Expansion Behavior of Plutonium $\ldots \ldots \ldots \ldots \ldots \ldots \ldots \ldots$

2. Plutonium-Gallium Equilibrium Diagram $\ldots \ldots \ldots \ldots \ldots \ldots \ldots \ldots \ldots \ldots$

3. Gallium Concentration Profile $\ldots \ldots \ldots \ldots \ldots \ldots \ldots \ldots \ldots \ldots \ldots \ldots \ldots$

4. Partial Plutonium-Gallium Phase Diagram $\ldots \ldots \ldots \ldots \ldots \ldots \ldots \ldots \ldots \ldots$

5. Plutonium Grain and Corresponding Gallium Profile $\ldots \ldots \ldots \ldots \ldots \ldots \ldots \ldots$

6. Microprobe High-Low Gallium in Cast Alloy Versus Homogenization Time $\ldots \ldots \ldots 5$

7. Microprobe High-Low Gallium in Wrought Alloy Versus Homogenization Time ...... 6

8. Grain Size Versus Homogenization Time for Cast Structure $\ldots \ldots \ldots \ldots \ldots \ldots$

9. Comparison of X Ray and $150-\mathrm{ksi}$ Pressure on Homogenization $\ldots \ldots \ldots \ldots \ldots$

10. Effect of Composition and 150-ksi Pressure on the Density of

Plutonium-Gallium Alloys $\ldots \ldots \ldots \ldots \ldots \ldots \ldots \ldots \ldots \ldots \ldots$

11. Density Versus Pressure for Pu-1 wt $\%$ Ga Alloy $\ldots \ldots \ldots \ldots \ldots \ldots \ldots \ldots \ldots$

12. Flow Diagram of Experimental Program $\ldots \ldots \ldots \ldots \ldots \ldots \ldots \ldots \ldots \ldots$

13. Density of Pu-Ga Alloys after $85-k s i$ Isostatic Pressure $\ldots \ldots \ldots \ldots \ldots \ldots \ldots \ldots$

14. Metallography of Fully Homogenized Pu-0.4 wt $\%$ Ga Alloy $\ldots \ldots \ldots \ldots \ldots$

is. Metallography of Fully Homogenized Pu-0.7 wt $\%$ Ga Alloy $\ldots \ldots \ldots \ldots \ldots \ldots$

16. Metallography of Fully Homogenized Pu-1 wt $\%$ Ga Alloy $\ldots \ldots \ldots \ldots \ldots \ldots$

17. Metallography of As-Cașt Pu-1 wt $\%$ Ga Alloy $\ldots \ldots \ldots \ldots \ldots \ldots \ldots \ldots$

18. Isostatically Pressed Density Versus Homogenization Time for Wrought Pu-1 wt \% Ga Alloy, Rolled to Various Percent Reductions . . . . 15

19. Homogenization Time Versus Percent Reduction for $25,50,75$, and $90 \%$ Homogenization $\ldots \ldots \ldots \ldots \ldots \ldots \ldots \ldots \ldots \ldots \ldots \ldots \ldots \ldots \ldots$

20. Metallography of Rolled $10 \%$, Pu-1 wt $\%$ Ga Alloy Not Homogenized $\ldots \ldots \ldots \ldots$

21. Metallography of Rolled $10 \%$, Pu-1 wt \% Ga Alloy after 10-Hour Homogenization 
22. Metallography of Rolled 50\%, Pu-1 wt \% Ga Alloy Not Homogenized

23. Metallography of Rolled $50 \%$, Pu-1 wt \% Ga Alloy after 3-Hour Homogenization

24. Metallography of Rolled $90 \%$, Pu-1 wt $\%$ Ga Alloy Not Homogenized $\ldots \ldots \ldots 18$

25. Metallography of Rolled $90 \%$, Pu-1 wt $\%$ Ga Alloy after 48-Minute

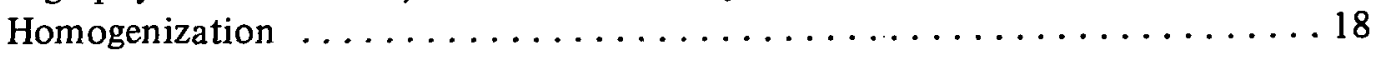

26. Comparison of Empirical, Thin Film, and Sinusoidal Gallium Concentration Profiles

27. Actual and Theoretically Predicted Density Versus Homogenization Time $\ldots \ldots \ldots 21$

28. Theorized Gallium Concentration Profile for As-Cast Pu-1 wt \% Ga Alloy ... . . . . 22

29. Plutonium Tensile Yield Strength Versus Gallium Composition . . . . . . . . . 24

30. Nonuniform Gallium, Mechanical Propertics, and Deformation in a Grain of Pu-1 wt \% Ga Alloy .25

31. A Comparison of Actual and Theoretically Predicted

Homogenization Time Versus Percent Reduction 26 


\section{A CKNOW LED GMENTS}

The author gratefully acknowledges the people whose-efforts made this report possible. In particular, the author would like to thank. Dr. W. L. Bradley for his counseling and encouragement, Mrs. P. Norton for the speed with which she typed and compiled the report, Messrs. R. L. Pratt and M. W. Maulfair for their outstanding experimental support, and Dr. J. H. Doyle for his valuable computer assistance regarding thin-film and sinusoidal diffusion solutions. 


\title{
A STUDY OF HOMOGENIZATION RATES IN \\ PLUTONIUM-1 WEIGHT PERCENT GALLIUM ALLOY \\ AS A FUNCTION OF \\ PERCENT REDUCTION BY COLD ROLLING
}

\author{
R. Jack Erfurdt
}

\begin{abstract}
Isostatic pressing for 30 minutes at 85,000 psi was used to determine the effect of cold rolling on the homogenization rates of Pu-1 wt $\%$ Ga alloy. A curve of density versus gallium composition was determined for 10 homogenized and isostatically pressed $\mathrm{Pu}-\mathrm{G} \mathbf{a}$ alloys between 0.1 and $1.0 \mathrm{wt} \%$ gallium. It was determined that delta phase $\mathrm{Pu}-\mathrm{Ga}$ alloys below $0.7 \mathrm{wt} \%$ gallium are partially transformed to alpha phase when isostatically pressed at room temperature to $85,000 \mathrm{psi}$. Samples from a Pu-1 wt $\% \mathrm{Ga}$ alloy ingot, rolled to $0,10,30,50,70$, and $90 \%$ reduction, were homogenized for various lengths of time at $450{ }^{\circ} \mathrm{C}$. Curves of isostatically pressed density versus homogenization time were generated for each percent reduction. Four levels of homogeneity, $25,50,75$, and $90 \%$, were evaluated. Each level of homogeneity was represented by an isostatically pressed density. Homogenization time as a function of percent reduction . was generated for each degree of homogeneity.
\end{abstract}

\section{INTRODUCTION}

Unalloyed plutonium solidifies at $640^{\circ} \mathrm{C}$. Upon cooling to room temperature, it undergoes six allotropic phase transformations. An idealized temperature-expansion curve and some crystallographic data for unalloyed plutonium are shown in Figure 1 and Table $1,{ }^{1}$ respectively. Certain concentrations of gallium stabilize plutonium in the delta phase. A plutonium-gallium phase diagram is shown in Figure 2. ${ }^{2}$ Note from the diagram that $\mathrm{Pu}-1$ wt $\% \mathrm{Ga}$ alloy, once solidified, will exist in two phases, epsilon and delta. The alloy also passes through two two-phase regions, liquid plus epsilon and epsilon plus delta.

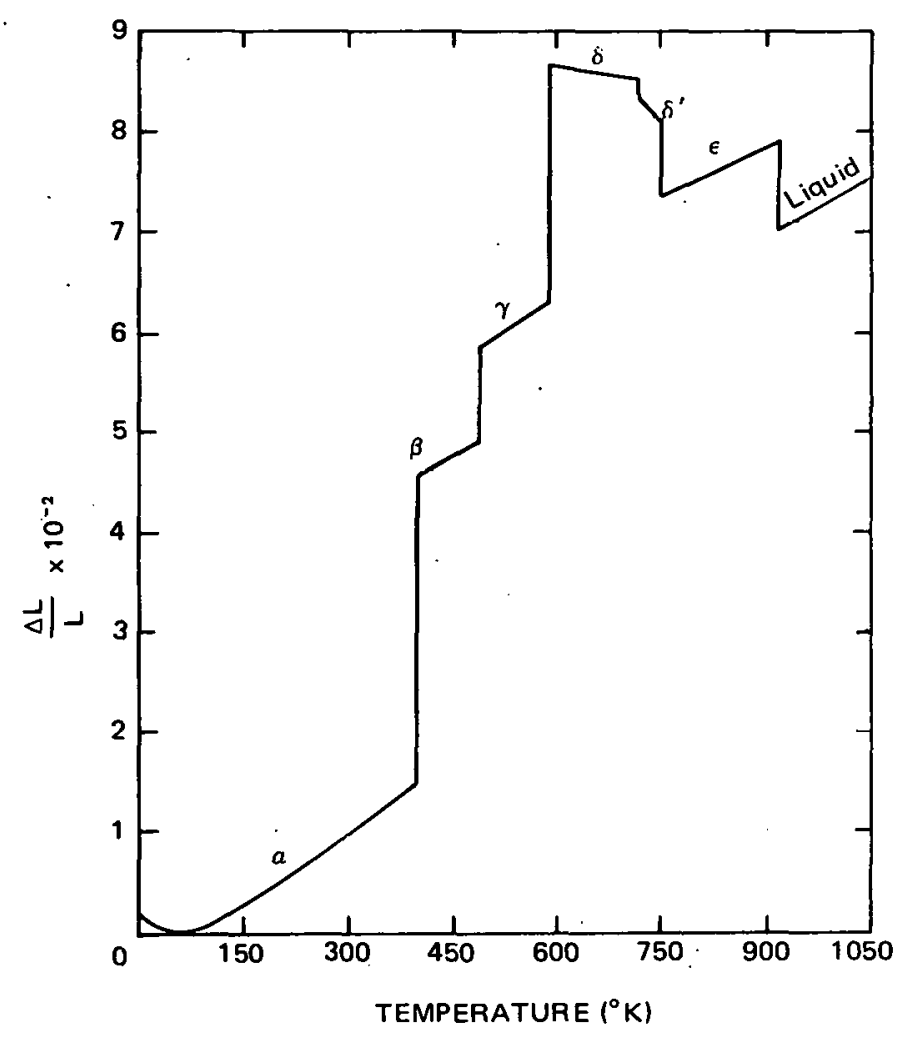

FIGURE 1. Idealized Temperature Expansion Behavior of Plutonium.

Microsegregation (coring) of gallium occurs as $\mathrm{Pu}-\mathrm{Ga}$ alloys cool through the epsilon plus delta phase region. ${ }^{3-5}$ A theoretical gallium profile for two as-cast grains in a $\mathrm{Pu}-1 \mathrm{wt} \% \mathrm{Ga}$ alloy is shown in Figure $3 .^{5}$ As a result of coring, an as-cast grain consists of a stable delta phase center surrounded by metastable delta phase. The metastable delta phase will transform directly to alpha phase when thermally cycled or mechanically stressed (i.e., rolled and isostatically pressed). 
TABLE 1. Crystal Structure Data for Plutonium.

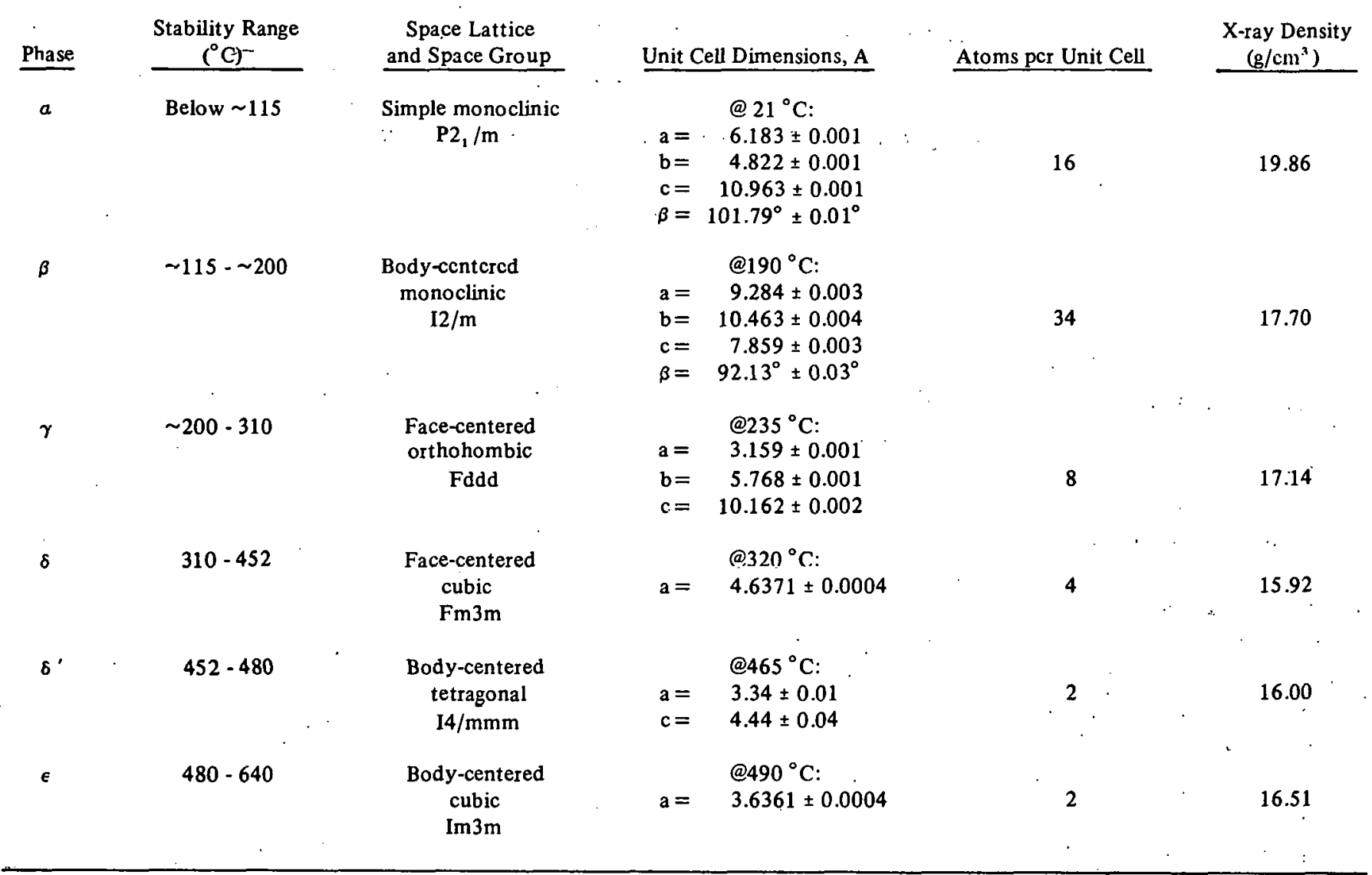

Coring may be eliminated in as-cast plutonium gallium alloys by a high temperature delta-phase anneal (homogenization). Pu-1 wt $\% \mathrm{Ga}$ alloy is commonly homogenized at $450^{\circ} \mathrm{C}$. During homogenization, gallium diffuses toward an equilibrium concentration of $1 \mathrm{wt} \%$, meaning it diffuses from grain centers to grain boundaries. The diffusion rate, or homogenization rate, is a function of the diffusion distance (as-cast grain size), and the homogenization temperature used.

Homogenization rates have been determined for as-cast $\mathrm{Pu}-1 \mathrm{wt} \% \mathrm{Ga}$ alloy as a function of grain size. ${ }^{4}$ The process of rolling distorts the grain structure of metals such that the diffusion distance for homogenization should be a function of percent reduction. This project was initiated to determine the effect of percent reduction by rolling on the rate of homogenization of a cored $\mathrm{Pu}-1$ wt $\% \mathrm{Ga}$ alloy.

\section{LITERATURE SURVEY}

Gallium coring occurs during the cooling of $\mathrm{Pu}-\mathrm{Ga}$ alloys from the liquidus to room temperature. Coring is described as a variation in gallium concentration within each grain, the central portion having a higher gallium concentration than the grain boundary. For Pu-1 wt \% Ga alloy, the as-cast delta phase grains have gallium concentrations as high as $1.8 \mathrm{wt} \%$ at their centers and are nearly depleted in gallium at their grain boundaries. It has been determined that coring observed across individual delta-phase grains results from the epsilon to delta phase transformation. ${ }^{3,4}$ Coring from the transformation results from the diffusivity of $\mathrm{Pu}$ and $\mathrm{Ga}$ in the epsilon phase relative to the delta phase. The chemical diffusivity of $\mathrm{Pu}$ and $\mathrm{Ga}$ in the epsilon is $\sim 10^{-7} \mathrm{~cm}^{2} / \mathrm{sec}$; whereas diffusivity of $\mathrm{Pu}$ and $\mathrm{Ga}$ in delta phase is only $\sim 5 \times 10^{-10} \mathrm{~cm}^{2} / \mathrm{sec}^{7}$ 


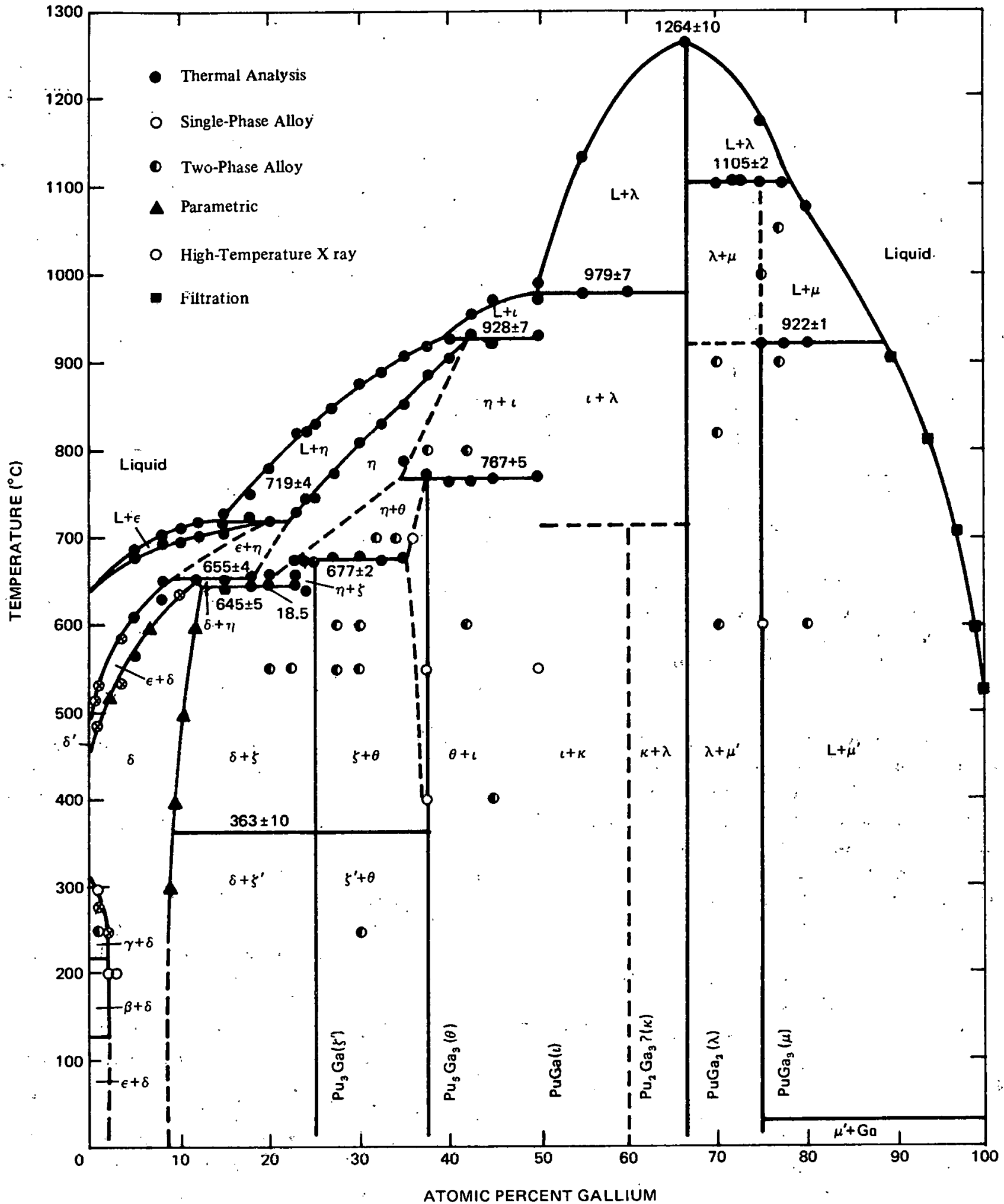

FIGURE 2. Plutonium-Gallium Equilibrium Diagram. 


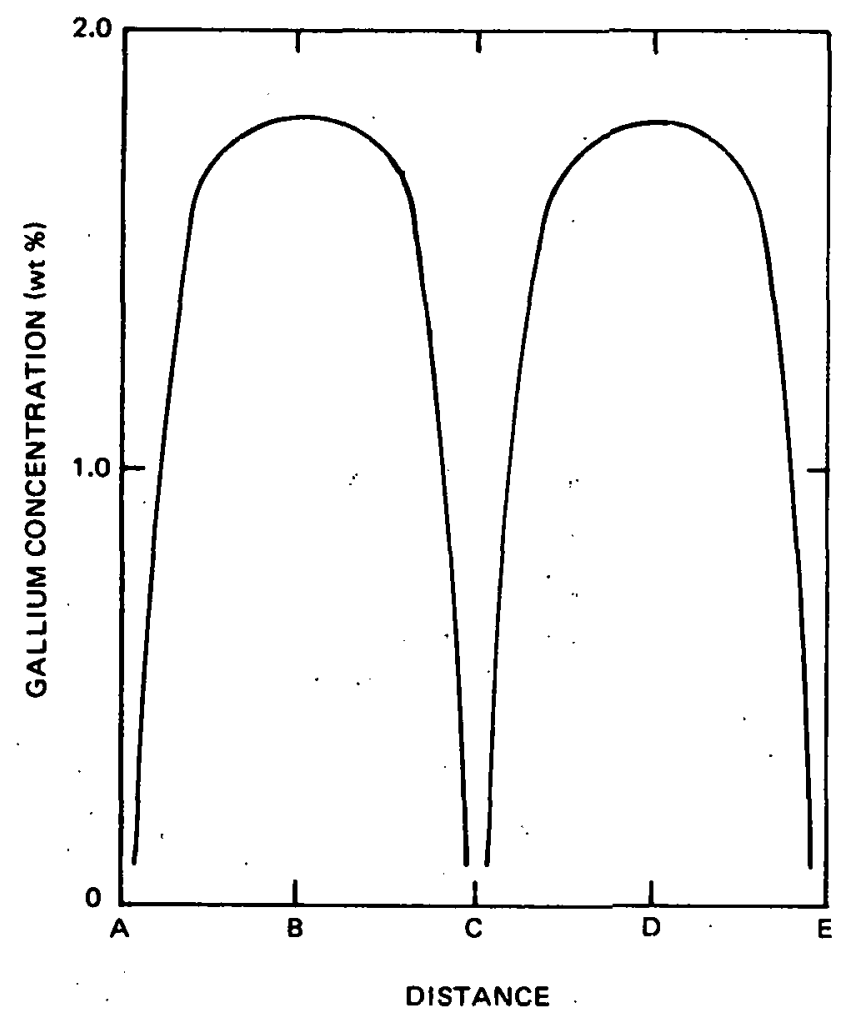

FIGURE 3. Theoretical Gallium Concentration Profile of Two Delta Phase Grains. (Grain Boundaries at Points A, C, and E, and Grain Centers at Points $B$ and D.)

By using the lever rule (for the epsilon plus delta phase region) and the partial equilibrium diagram shown in Figure 4, the theoretical gallium profile for two adjacent delta grains has been determined. ${ }^{5}$ Gallium concentration profiles were determined with an electron microprobe. A comparison of theoretical and measured gallium concen tration profiles is shown in Figure $5 .^{5}$

The low gallium delta-phase area, near the grain boundaries, is metastable and can transform to alpha phase during cold rolling, ${ }^{4}$ metallographic polishing, ${ }^{8}$ uniaxial compression, ${ }^{9}$ isostatic pressing, ${ }^{4}$ cold storage, ${ }^{10}$ and thermal cycling. ${ }^{11}$ Delta-phase homogenization treatments are required to eliminate the metastable areas. Homogenization occurs by diffusion of gallium to the mean concentration.

The electron microprobe was used to study homogenization behavior of cast $\mathrm{Pu}-1 \mathrm{wt} \% \mathrm{Ga}$

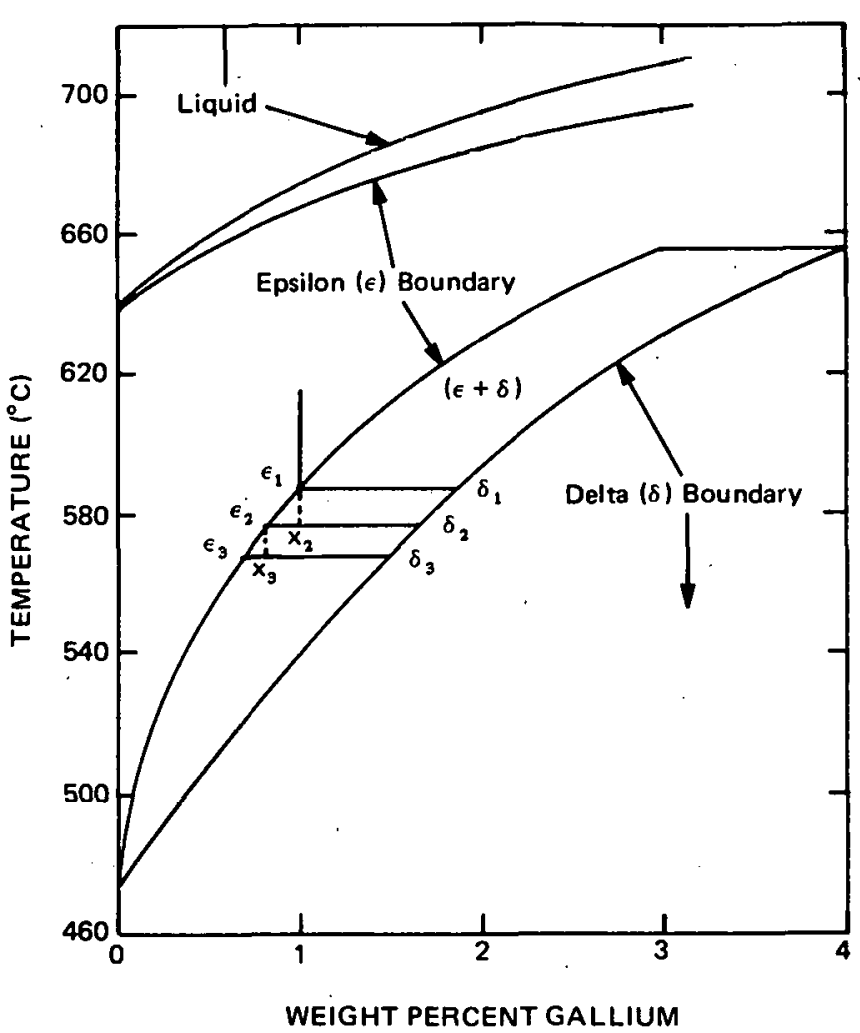

FIGURE 4. Partial Plutonium-Gallium Phase Diagram Showing Procedure for Determining the Gallium Profile.

alloy. ${ }^{3}$ The technique used was to determine the high and low gallium concentrations within a sample after various amounts of homogenization at a given temperature. A plot of high and low gallium concentration versus homogenization time at $500^{\circ} \mathrm{C}$ for a "relatively pure" $\mathrm{Pu}-1$ wt $\%$ $\mathrm{Ga}$ alloy sample is shown in Figure $6 .^{3}$ The cored grain size of the alloy was approximately $0.010 \mathrm{~mm}$. Homogenization time for the sample was estimated to be 60 hours.

For comparison, the electron microprobe was used to study homogenization behavior of a relatively impure sample of $\mathrm{Pu}-1$ wt $\%$ Ga alloy rolled to $37.5 \%$ reduction. ${ }^{3}$ A plot of high and low gallium concentration versus homogenization time at $500{ }^{\circ} \mathrm{C}$ for that sample is shown in Figure $7 .^{3}$ The as-cast grain size of the sample was not given. It is assumed that the pure and impure samples were of the same as-cast grain size. The rolled alloy was estimated to be 


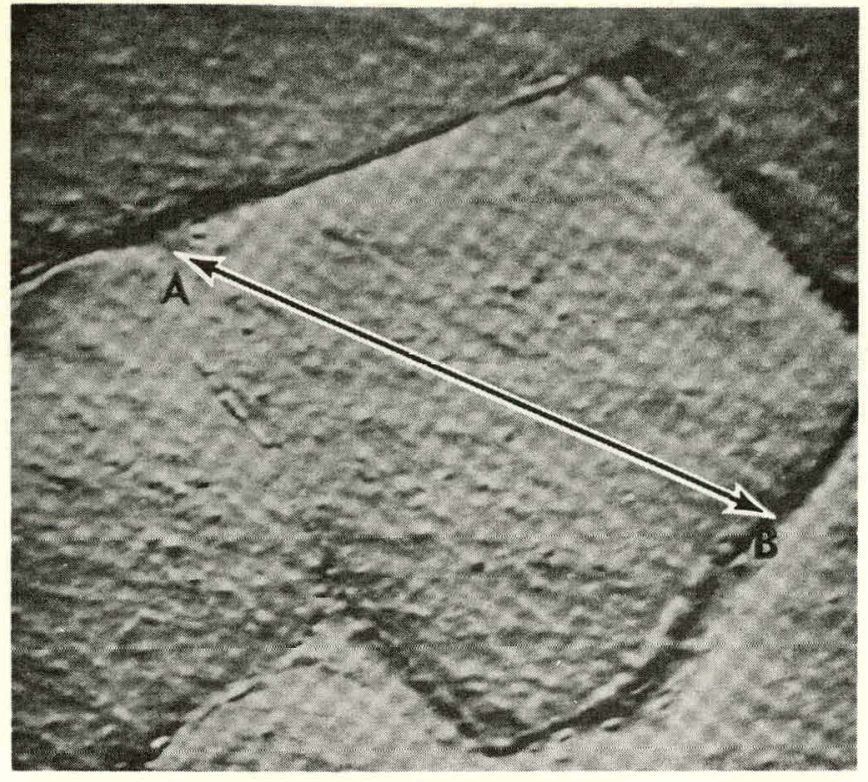

(a) Backscattered Electron Image of Sample Cooled $1{ }^{\circ} \mathrm{C}$ per Minute, Showing the Area of Analysis. Magnification 500X.

(b) Gallium Concentration Profiles Superimposed over Theoretical Curve.

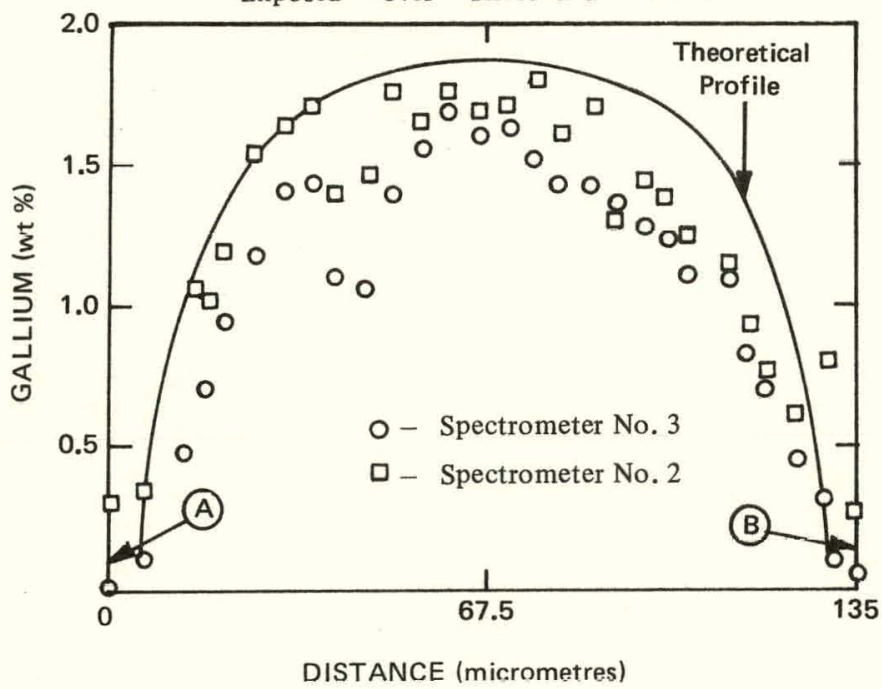

FIGURE 5. Electron Image of Sample and Corresponding Gallium Profiles.

homogenized in 14 hours. Some areas of low gallium concentration remained throughout homogenization. The areas of low gallium were attributed to a low solubility of gallium in a liquid eutectic phase. This would seem plausible, particularly since the rolled sheet was relatively

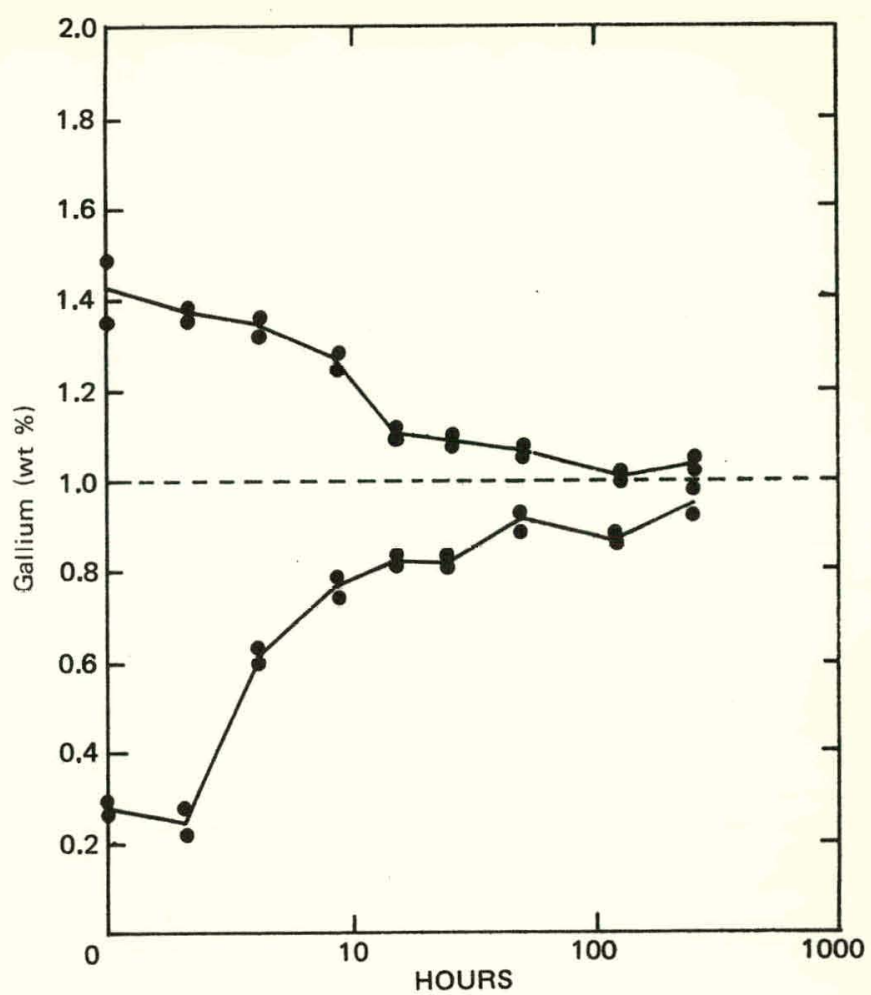

FIGURE 6. High and Low Gallium Concentration Levels Found in the Relatively Pure Cast Plutonium-1 Weight Percent Gallium Alloy that had been Annealed at $500{ }^{\circ} \mathrm{C}$.

impure (270 ppm iron), and it is known that the $\mathrm{Pu}_{6} \mathrm{Fe}$ eutectic melts at $410^{\circ} \mathrm{C}$.

An X-ray diffraction, line broadening technique was used to determine the rate of homogenization at $450{ }^{\circ} \mathrm{C}$ of $\mathrm{Pu}-1$ wt $\% \mathrm{Ga}$ alloy as a function of grain size. ${ }^{4}$ A plot of as-cast grain size versus anneal time at $450{ }^{\circ} \mathrm{C}$ required for homogenization is shown in Figure 8. In addition, the effect of annealing time for the same alloy at $450^{\circ} \mathrm{C}$ on the rate of homogenization as indicated by $\mathrm{X}$-ray line broadening and density after a 150,000 psi compression is shown in Figure 9. ${ }^{4}$ Even though the two methods compare, it is apparent that the compression technique gives a larger estimate of homogenization time than does the X-ray technique. Extrapolation of the compression data indicates that approximately 53 hours would be required for homogenization, whereas the X-ray data indicate 40 hours. The effect of gallium composition and 150,000 psi uniaxial compression on the density of fully homogenized Pu-Ga alloys is shown in Figure 10. ${ }^{4}$ 


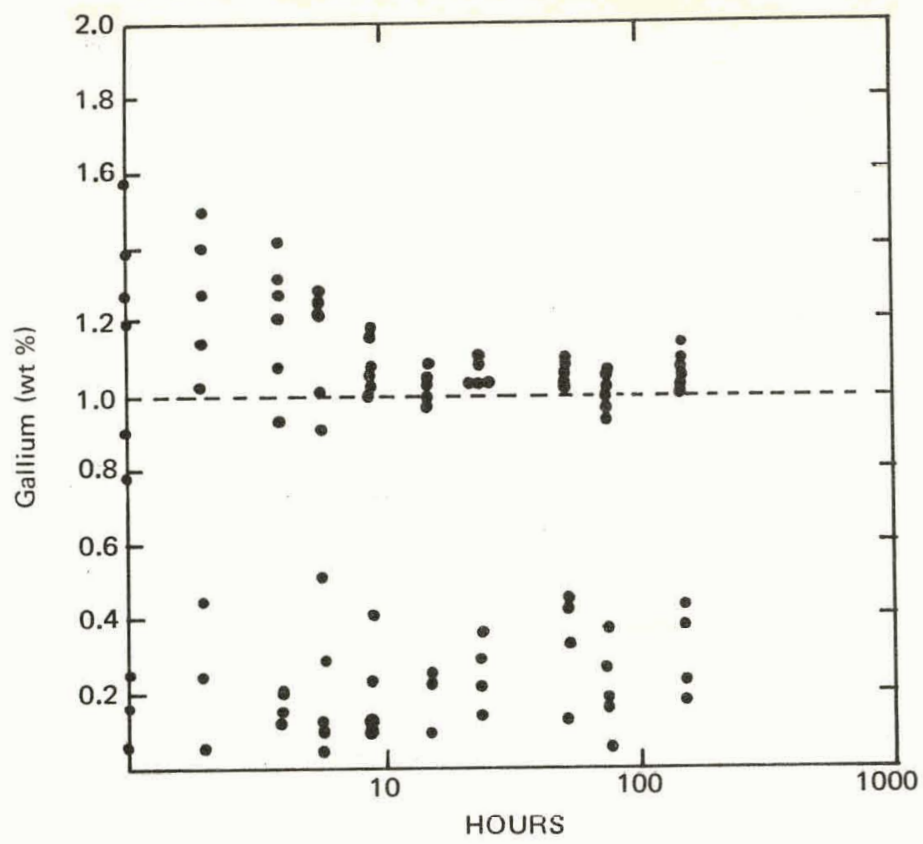

FIGURE 7. High and Low Gallium Concentration Levels Found in Specimens of the Relatively Impure Rolled Plutonium-1 Weight Percent Gallium Alloy that had been Annealed at $500{ }^{\circ} \mathrm{C}$.

FIGURE 8. Relation Between Grain Size and Anneal Time Required for Homogenization in a Cored Pu-1 Wt \% Ga Delta-Stabilized Alloy.

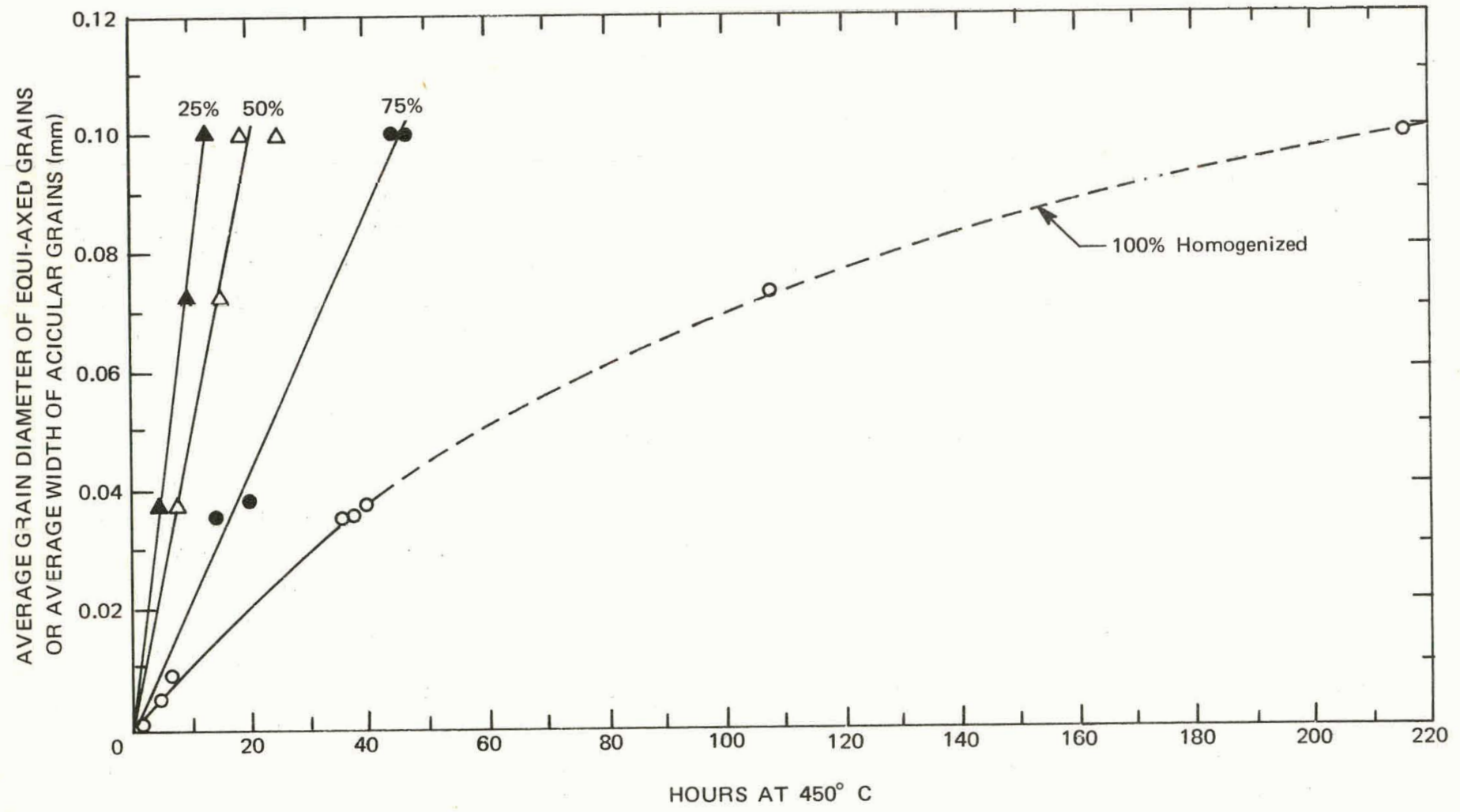




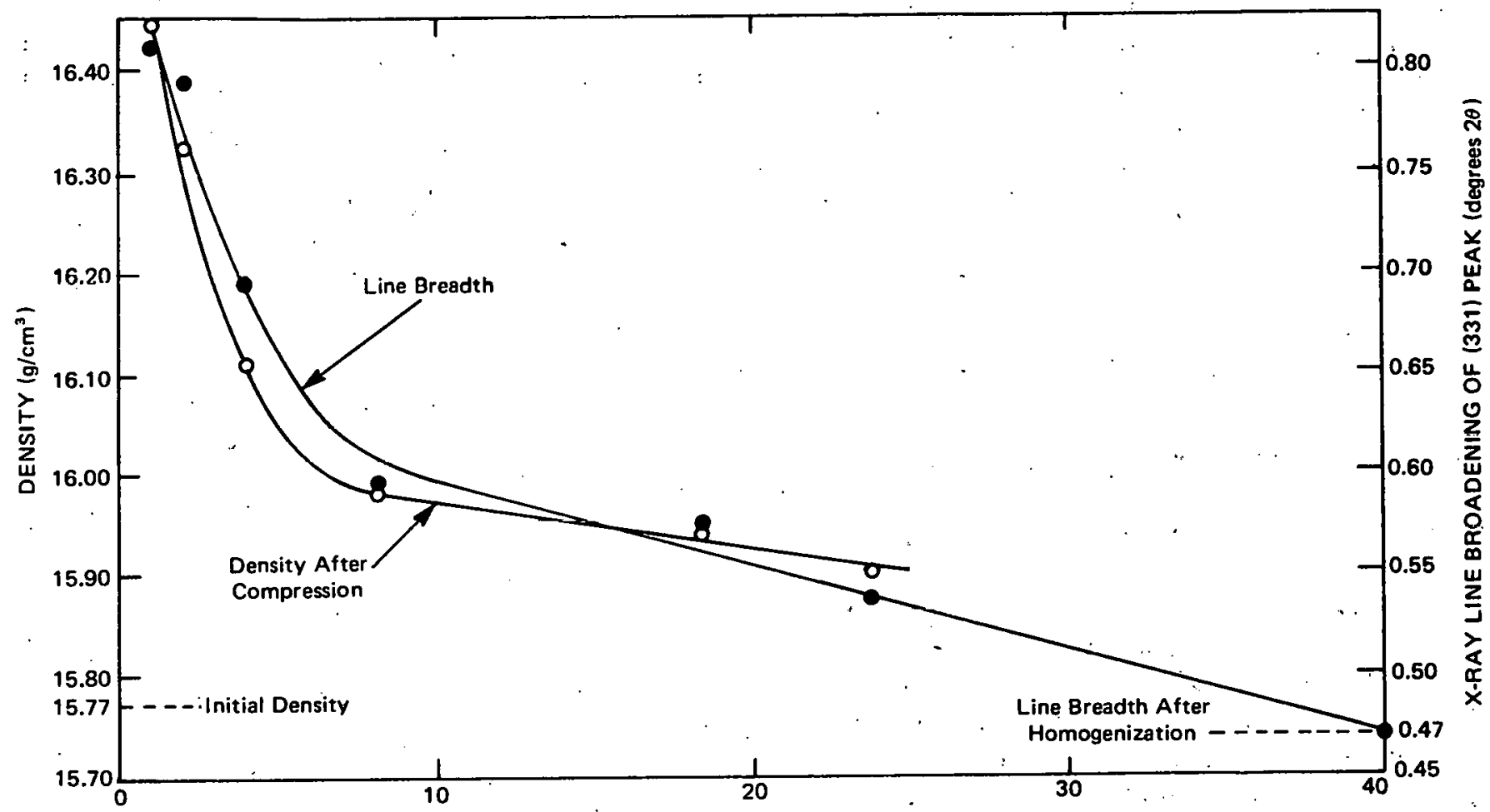

FIGURE 9. The Effect of Anneal Time at $450{ }^{\circ} \mathrm{C}$ on Rate of Homogenization as Indicated by $\mathrm{X}$-ray Line Broadening and Density after a 150,000 psi Compression in Pu-1 Wt \% Ga Alloy.

FIGURE 10. Effect of Composition and 150,000 psi Pressure on Density in Pu-Ga Alloys.

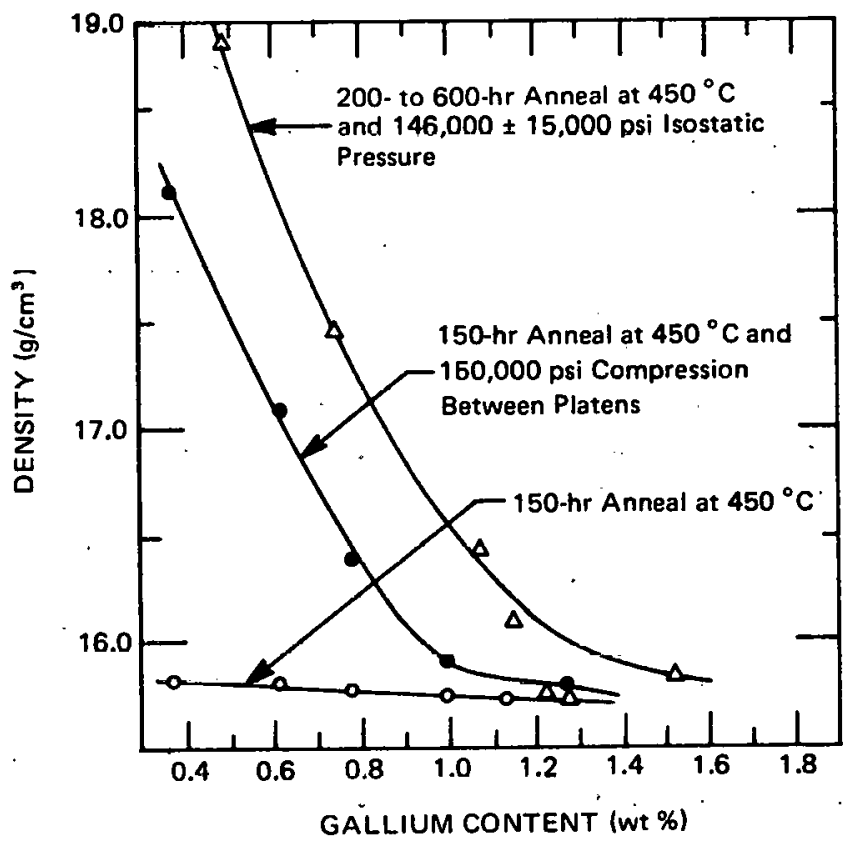


It may be noted from the data that 150,000 psi will cause some density change in fully homogenized Pu-1 wt \% Ga alloy. The effect of isostatic pressure and uniaxial compression on the density of a Pu-1 wt \% Ga alloy that had been annealed for one hour at $425{ }^{\circ} \mathrm{C}$ is shown in Figure 11. From the data, it is evident that the isostatic pressure-density curve extrapolates well to 150,000 psi uniaxial compression.

Based on the data presented, it may be seen that a plot showing the rate of homogenization of a sample is somewhat dependent on the criteria used to define homogeneity. The relationship between grain size and anneal time required for various degrees of homogenization, as determined by X-ray line broadening is shown in Figure 8. If 150,000 psi had been used as the criterion for determining homogeneity, it is expected that the curves would have been shifted to the right because it would have taken longer to adequately homogenize a sample so no alpha phase would form during compression.

It is known that the distance over which diffusion occurs is described by the following equation: ${ }^{12,13}$

$$
\mathrm{X}=\mathrm{K} \sqrt{\mathrm{Dt}}
$$

where

$X$ - is distance over which significant transport by diffusion has occurred.

$\mathrm{K}$ - is a constant, dependent on the initial concentration distribution geometry.

D - is diffusivity, which is a function of temperature. Diffusivity may be assumed constant at a given temperature.

t - is elapsed time during which diffusion occurred.

The time necessary for homogenization will vary directly with the square of the diffusion distance;

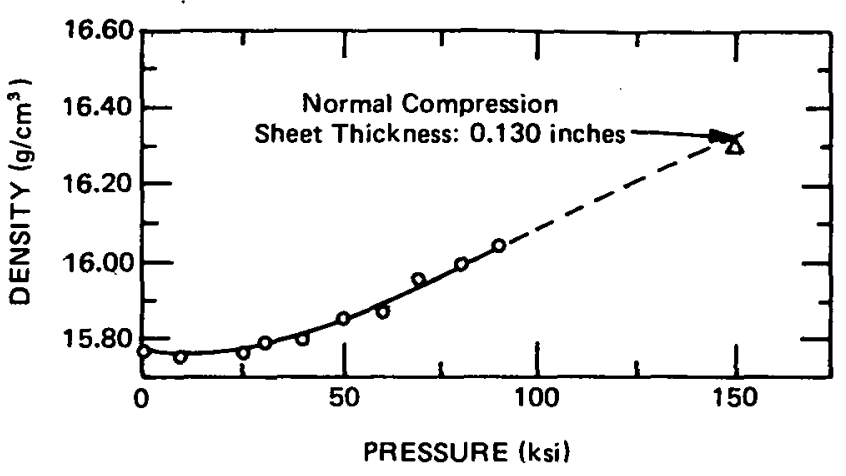

FIGURE 11. Effect of Isostatic Pressure and Compression on Density of a Cored Pu-1 Wt \% Ga Alloy Heat Treated for 1 Hour at $425^{\circ} \mathrm{C}$. Original Cored Grain Diameter: $0.037 \mathrm{~mm}$.

i.e., grain size. If rolling produces uniform deformation, then a reduction in thickness of the cored grain should occur and the homogenization time should be decreased accordingly.

\section{EXPERIMENTAL}

This section is alvided into two categories: (1) the experimental program, which describes the overall plan of collecting experimental data, and (2) experimental procedures, which describes experimental equipment and procedures used in expediting the experimental program.

\section{Experimental Program}

Isostatic pressing at 85,000 psi was used as the means of determining phase stability, and hence, the degree of homogenization possessed by Pu-1. wt $\% \mathrm{Ga}$ alloy. It was noted earlier that coring produces relatively large gallium variations across as-cast grains of Pu-Ga alloys. As a result, it was of interest to determine a calibration curve that describes the relationship of density, after 85,000 psi isostatic pressure, as a function of percent gallium. To determine whether the delta-to-alpha phase transformation by isostatic pressure was significantly affected by hold time 
at pressure, the samples were isostatically pressed a second time at the same parameters with a subsequent density determination.

It was intended that all homogenization rate data be generated at $450{ }^{\circ} \mathrm{C}$. The isostatically pressed density of cast $\mathrm{Pu}-1 \mathrm{wt} \% \mathrm{Ga}$ alloy as a function of homogenization time was first determined. Then, for comparison, similar data was generated for the alloy after it had been rolled to several percent reductions. A flow diagram depicting the overall experimental program is shown in Figure 12.

The unalloyed plutonium used for this project was vacuum induction melted and cast into an unheated $\mathrm{CaF}_{2}$-coated graphite mold. The resultant ingot was sampled for chemical analysis. The master ingot was used as feed for 10 castings that were alloyed to $0.1,0.2$, $0.3,0.4,0.5,0.6,0.7,0.8,0.9$, and 1.0 wt $\%$ gallium. The melt for each casting was poured into an unheated $\mathrm{CaF}_{2}$-coated graphite mold, and each ingot sampled for chemical analysis. It is estimated that the cooling rate of the alloys through the epsilon-plus-delta phase region exceeded $100^{\circ} \mathrm{C} / \mathrm{min}$, and therefore produced a cored-grain diameter of less than $0.020 \mathrm{~mm}$. As noted in Figure 8, 20 hours at $450{ }^{\circ} \mathrm{C}$ should fully homogenize $0.020-\mathrm{mm}$ diameter cored grains. To ensure complete homogenization, samples from the 10 alloys were homogenized for 135 hours at $450^{\circ} \mathrm{C}$. The metallographic structure of the $0.4,0.7$, and $1.0 \mathrm{wt} \%$ gallium samples was determined.

A 4- by 4- by 1.125 -in. ingot of $\mathrm{Pu}-1$ wt $\% \mathrm{Ga}$ alloy was cast from the remnants of the 10 ingots. The melt was cast into $\mathrm{a} \mathrm{CaF}_{2}$-coated mold that had been prcheated for 20 minutes at $680^{\circ} \mathrm{C}$. The ingot and mold were cooled through the epsilon-plus-delta phase region at approximately $6{ }^{\circ} \mathrm{C} / \mathrm{min}$. The metallographic structure of the as-cast ingot was determined from three perpendicular directions. This was an attempt to determine whether the structure was randomly oriented, and to characterize the size and shape of the cored grains. The ingot was sampled for chemical analysis. In addition, the 12 density samples were sawed from the ingot.
The remainder of the 4- by 4 - by 1.125 -in. ingot was rolled at 0.025 -in. per pass to $5 \%$ reduction, rotated $90^{\circ}$, and cross rolled another $5 \%$ for a total of $10 \%$ reduction. A second set of 12 samples was cut from the ingot. The ingot was rolled, cross rolled, and sampled at 30, 50, 70, and $90 \%$ reduction.

The metallographic structure of six samples was determined for comparison. The structure of a $10 \%$ as-rolled sample was compared to one rolled $10 \%$ and homogenized 10 hours at $450^{\circ} \mathrm{C}$. A sample rolled $50 \%$ was compared to one rolled $50 \%$ and homogenized for three hours at $450^{\circ} \mathrm{C}$. A $90 \%$ as-rolled sample was compared to one rolled $90 \%$ and homogenized 48 minutes at $450{ }^{\circ} \mathrm{C}$.

\section{Experimental Procedures}

This section describes the methods used for casting, homogenization, metallography, density, rolling, and isostatic pressing.

\section{Casting}

Castings were made by vacuum induction melting in an oxidized tantalum crucible and bottom pouring into a $\mathrm{CaF}_{2}$-coated graphite mold. During casting, the furnace chamber was evacuated below $0.050-\mathrm{mm} \mathrm{Hg}$. Generally, the charge was heated to $980^{\circ} \mathrm{C}$ and held at that temperature for 20 minutes prior to casting. After casting, the furnace was backfilled to $500-\mathrm{mm} \mathrm{Hg}$ with $\mathrm{Ar}$.

\section{Homogenization}

Homogenization was performed in a vacuum resistance heated furnace. The furnace was evacuated below $0.010 \mathrm{~mm} \mathrm{Hg}$ prior to heat treating. Samples were heated at approximately $15^{\circ} \mathrm{C} / \mathrm{min}$ to $450^{\circ} \mathrm{C}$ and held for a specified length of time. At the end of the homogenization, the furnace power was shut off and the furnace was backfilled to a pressure of $250-\mathrm{mm} \mathrm{Hg}$ with 


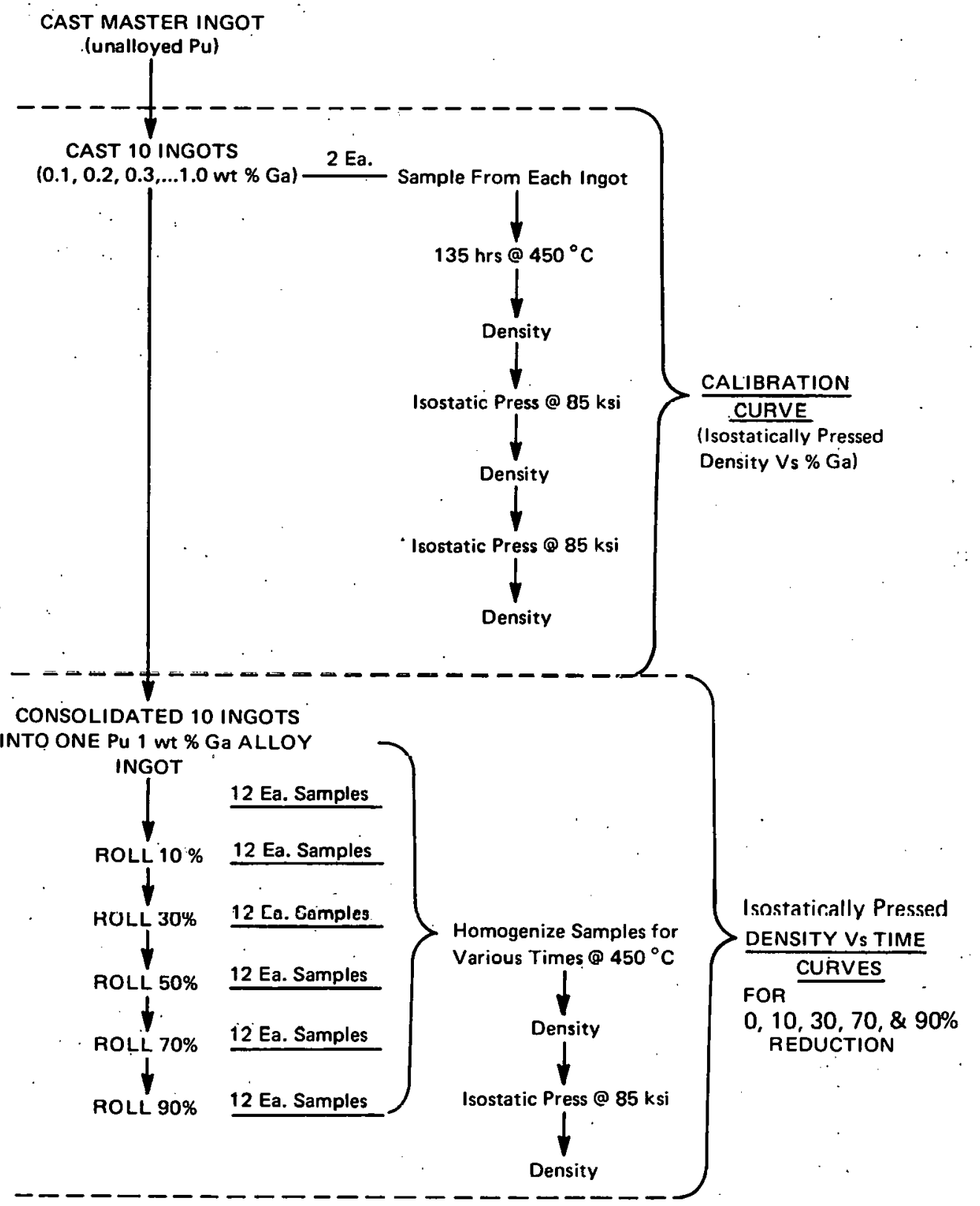

FIGURE 12. A Flow Diagram Depicting the Overall Experimental Program Used for this Project. 
argon. The samples were cooled from $450^{\circ} \mathrm{C}$ to $300^{\circ} \mathrm{C}$ at approximately $12^{\circ} \mathrm{C} / \mathrm{min}$.

\section{Metallography}

The following metallography procedures werc used:

1. The metal specimen was mounted in a 1-in. diameter by 1 -in. high cylinder of roomtemperature-setting epoxy.

2. Mounted samples were ground on 240- to 600 -grit silicon carbide paper using carbon tetrachloride as a lubricant.

3. The samples were hand polished with 5- and 6-micrometre diamond paste on nylon cloth using lapping oil as a lubricant.

4. The samples were hand polished with 1-micrometre diamond paste on a medium nap cloth using lapping oil as a lubricant.

5. The samples were polished for 3 hours on an automatic vibratory polisher with 0.25 micrometre diamond paste and a lubricant of mineral spirits.

6. The samples were electropolished for 2 minutes at 12 volts (D.C.) in a solution consisting of 8 parts orthophosphoric acid, 5 parts ethyl alcohol, and 5 parts ethylene glycol.

7. The samples were etched for 1 minute at 12 volts (D.C.) in a solution consisting of 116-g citric acid, 400-ml ethyl alcohol, $20-\mathrm{ml} \mathrm{KNO}_{3}$, and 100-ml $\mathrm{H}_{2} \mathrm{O}$.

8. The mounted samples were viewed in a variable power optical metallograph.

Flongated grains were produced when the alloy was cooled down through the delta-plus-epsilon phase region. The cored structure was best observed when the metallographic sample was etched. The coring was depicted as light-grain-center regions of high gallium concentration surrounded by darkgrain-boundary regions of low gallium.

Density

Densities were obtained by the hydrostatic weighing method. Coupons were suspended in a wire holder in a bath of monobromobenzene. Weights were determined using a Mettler Gram-Atic balance with densities estimated reproducible to within $\pm 0.002 \mathrm{~g} / \mathrm{cm}^{3}$ (one standard deviation).

Rolling

Rolling was accomplished on a two-high mill with 5 -in. diameter work rolls. The ingot was rolled . at 0.025 inch per pass.

Isostatic Pressing

The isostatic press used for this study has an 8-in. diameter by 6 -in. long chamber. Herculube-C oil was used as the pressure transmitting medium. An isolation chamber minimizes possible leaking of radioactive contamination. Pressure is transmitted to the interior via a rubber diaphragm.

\section{RESULTS AND ANALYSES}

Nominal chemical impurities of the master ingot are shown in Table 2. Chemical analysis of each ingot verified there were no significant impurities introduced during subsequent casting. The calibration curve of density after 85,000 psi isostatic pressure, as a function of weight percent gallium, is shown in Figure 13. The samples used for Figure 13 were chill cast, homogenized for 135 hours at $450^{\circ} \mathrm{C}$, and isostatically pressed twice, both times for 30 minutes at ambient temperature. Note from the second isostatic pressing that hold time at pressure does not significantly affect the resultant density.

The data indicate that plutonium with less than 0.7 wt $\%$ gallium undergoes some delta $\rightarrow$ alpha 
TABLE 2. Nominal Impurities in Plutonium Master Ingot.

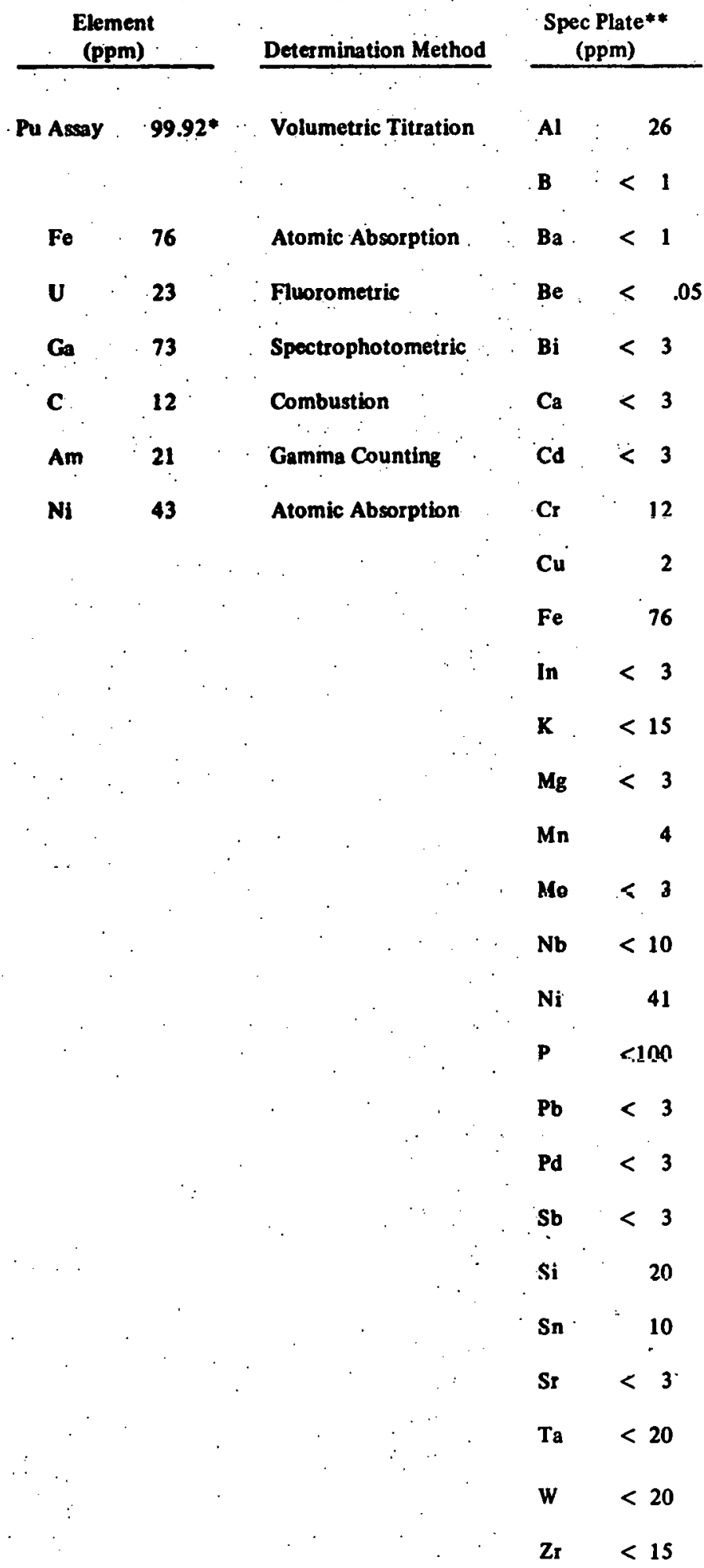

*weight percent.

**spec plate results determined by emission spectroscopy. transformation when isostatically pressed at $85,000 \mathrm{psi}$. With the information presented in the calibration curve, the geometric shape of a cored grain and the gallium profile across that grain, a theoretical density of the cored alloy may be calculated.

FIGURE 13. Relative Stability of Pu.

Ga Alloys as a Function of Density.

Legend

- Cast $\rightarrow$ Homogenized 135 hours at $450^{\circ} \mathrm{C}$

$\Delta$ Cast $\rightarrow$ Humogenized 135 hours at $450^{\circ} \mathrm{C} \rightarrow$ Isostatically Prcss (30 minutes at $85,000 \mathrm{psi}$ ) .

a Cast $\rightarrow$ Homogenized 135 hours at $450^{\circ} \mathrm{C} \rightarrow$ Isostatically Pressed Twice ( 30 minutes at 85,000 psi)

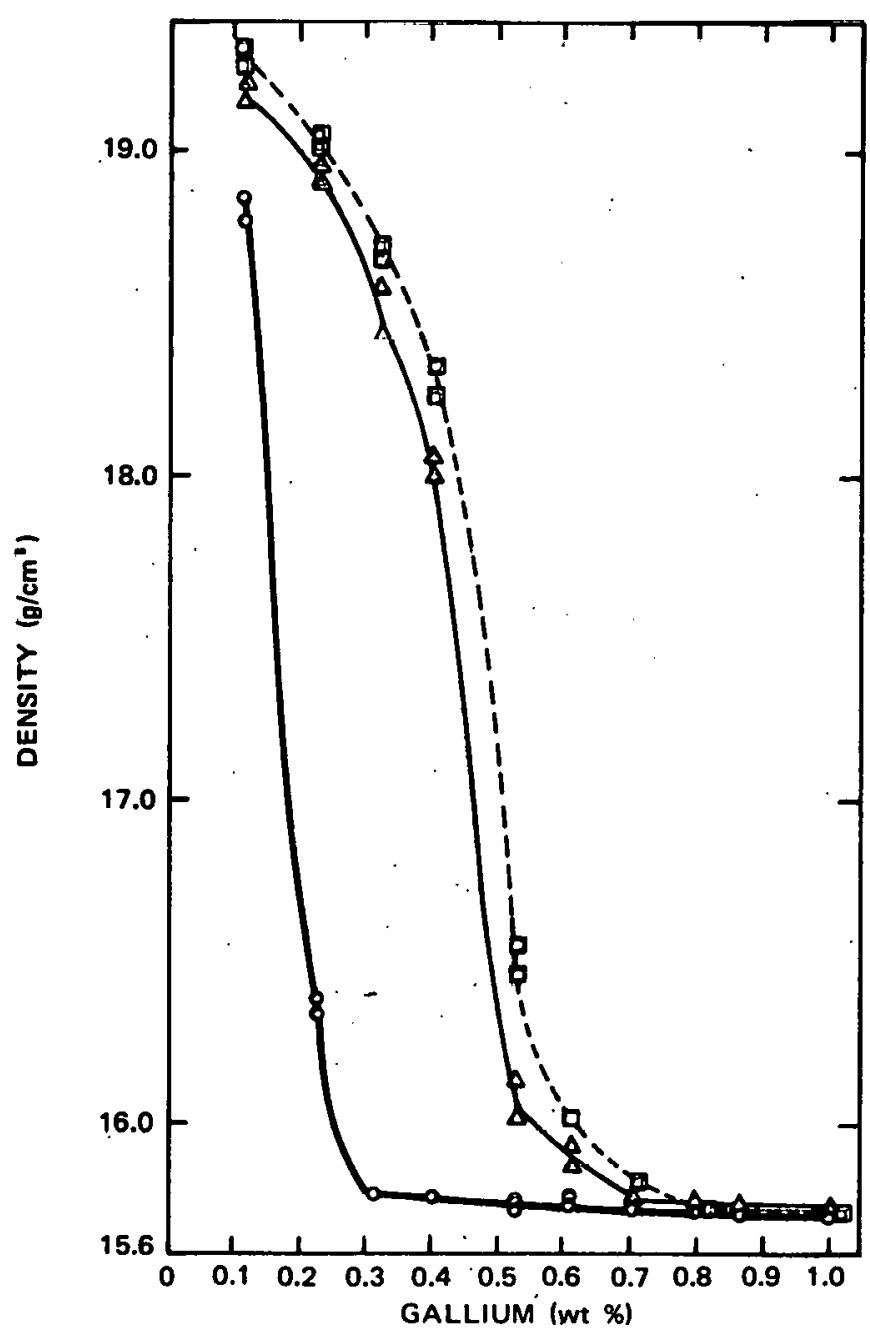


The metallographic structure of three $\mathrm{Pu}-\mathrm{Ga}$ alloys after isostatic pressing was compared. The structure of a $0.4 \mathrm{wt} \% \mathrm{Ga}$ alloy is shown in Figure 14. The alloy sample shown had been chill cast, homogenized at $450{ }^{\circ} \mathrm{C}$ for 135 hours, and isostatically pressed twice at $85,000 \mathrm{psi}$, both times for 30 minutes at ambient temperature. The sample contained approximately $70 \%$ alpha phase and $30 \%$ delta phase as determined by density. Alpha and delta phases are not identifiable in the photomicrograph.

Note from the calibration curve that the sample density was approximately $18.3 \mathrm{~g} / \mathrm{cm}^{3}$ after the second isostatic pressing. Based on theoretical alpha- and delta-phase densities of 19.7 and 15.7 $\mathrm{g} / \mathrm{cm}^{3}$, respectively, a density of $18.3 \mathrm{~g} / \mathrm{cm}^{3}$ corresponds to approximately $70 \%$ alpha and $30 \%$ delta phase. For comparison, the structure of 0.7 and $1.0 \mathrm{wt} \%$ gallium are shown in Figures 15 and 16 , respectively. Both alloys are nearly $100 \%$ delta phase.

FIGURE 14. Fully Homogenized Pu$0.4 \mathrm{Wt} \%$ Ga Alloy. (Etched - 200X).

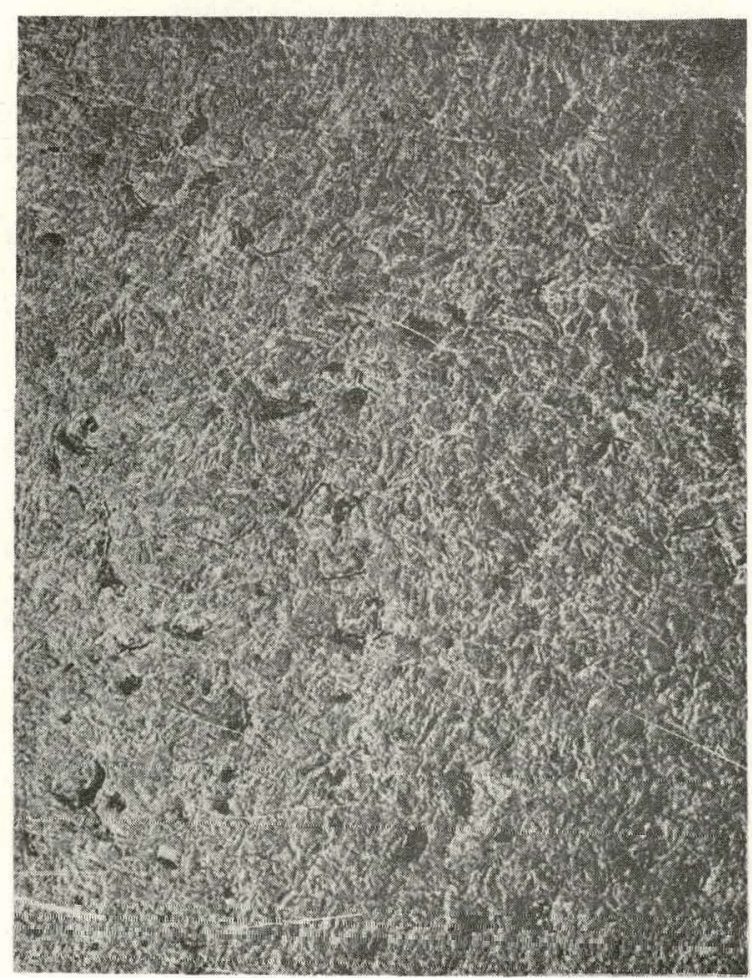

The sample in Figure 15 had been chill cast, homogenized at $450{ }^{\circ} \mathrm{C}$ for 135 hours, and isostatically pressed twice at 85,000 psi, both times at ambient temperature for 30 minutes. The sample contained approximately $99 \%$ delta phase and $1 \%$ alpha phase, as determined by density. The sample in Figure 16 had been chill cast, homogenized for 135 hours at $450{ }^{\circ} \mathrm{C}$, and isostatically pressed twice at 85,000 psi, both times at ambient temperature for 30 minutes. The sample was $100 \%$ delta phase, as determined by density. The metallographic structure of the as-cast 4- by 4 - by 1.125 -in. ingot is shown in Figure 17. The sample structure in Figure 17 contains randomly oriented elongated grains. The light colored, elongated delta-phase grains are surrounded by the darker alpha phase in the grain boundary and triple point regions. The black spots are etch pits. Metallographic structure determined from three perpendicular directions was identical. This verified that the grains were randomly oriented. To make any

FIGURE 15. Metallographic Structure of a Fully Homogenized $0.7 \mathrm{Wt} \%$ Ga Alloy Sample. The Dark Spots are Etch Pits. Etched - 200X.

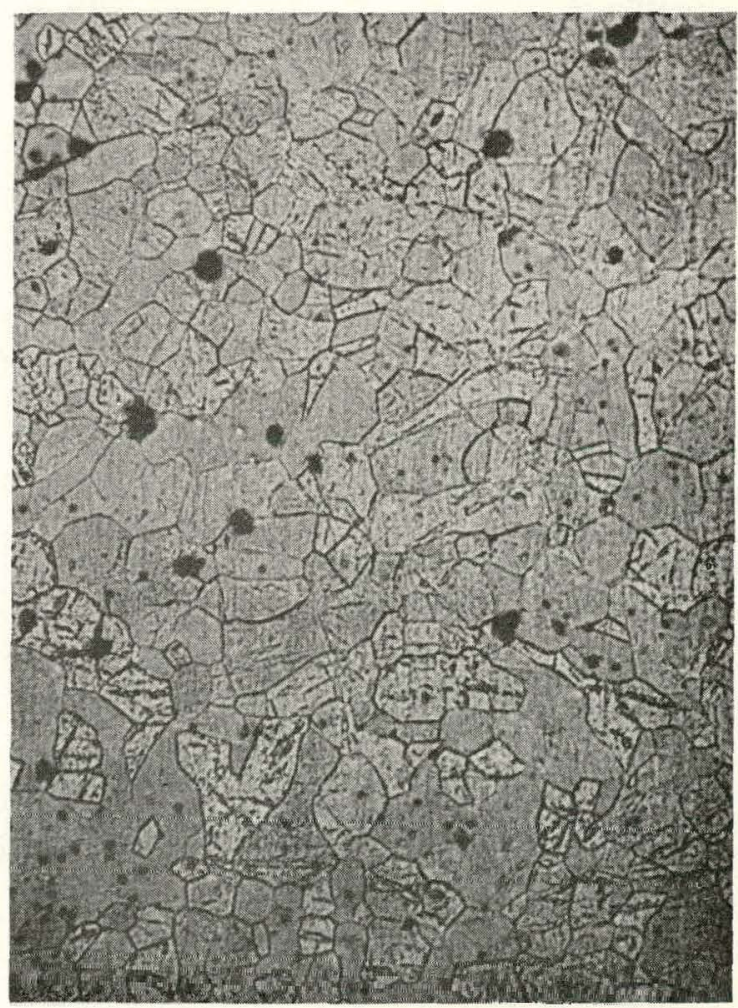


theoretical diffusion computations, a model of the cored grain must be used. Based on the metallographic results, a right cylinder of $0.050-\mathrm{mm}$ diameter was assumed as the grain geometry.

The effects of rolling and subsequent isostatic pressing on the density of the as-cast, nonhomogenized, Pu-1 wt \% Ga alloy ingot are shown in Table 3. Note that, except for the first 10\% reduction, the sample densities varied directly with percent reduction. The results of density as a function of homogenization time for the ingot as-cast, and rolled to $10,30,50,70$, and 90\% reductions are shown in Figure 18.

It is obvious that the ingot homogenizes faster as the percent reduction increases. The isostatically pressed density of the cored, as-cast ingot was $16.23 \mathrm{~g} / \mathrm{cm}^{3}$. The homogenized density, corresponding to $100 \%$ delta phase, was 15.74 $\mathrm{g} / \mathrm{cm}^{3}$. Therefore, the total density change of the cored as-cast sample was $0.49 \mathrm{~g} / \mathrm{cm}^{3}$. Based on the density change, it was assumed that a

FIGURE 16. Metallographic Structure of a Fully Homogenized 1 Wt \% Ga Alloy. Etched - 200X.

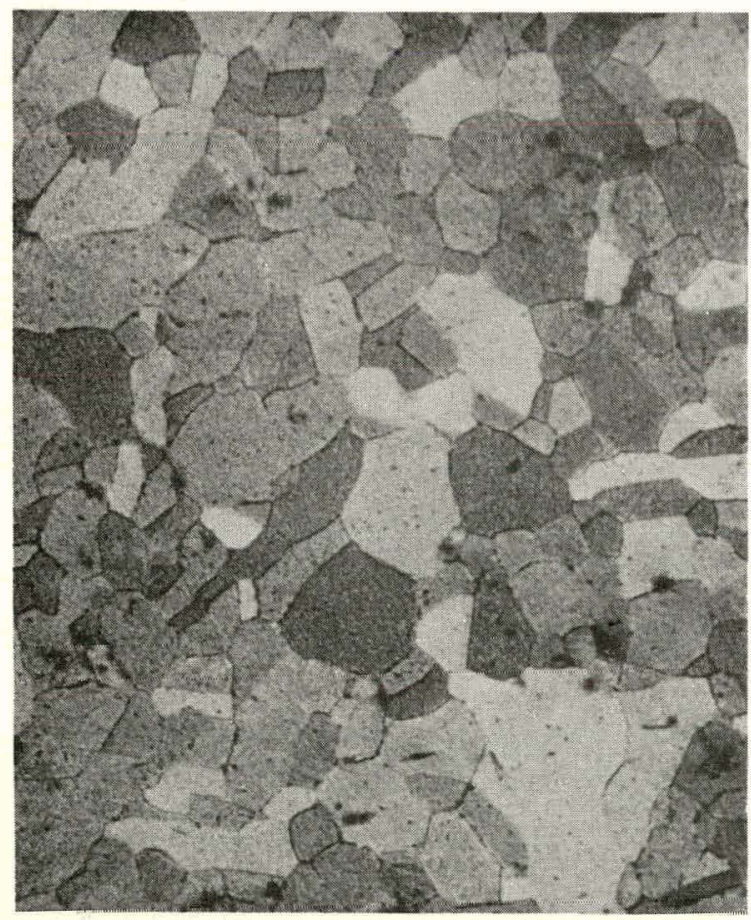

sample density of $[16.23-(0.49 \times 0.25)]$ or $16.115 \mathrm{~g} / \mathrm{cm}^{3}$ corresponds to $25 \%$ homogenization.

By the same technique, densities of 15.990 , 15.865 , and 15.790 correspond to 50,75 , and $90 \%$ homogenization, respectively. Using those density values and the plot of density versus homogenization time shown in Figure 18, the curves of homogenization versus annealing time shown in Figure 19 were generated. An interpretation of the results presented in Figure 19 will be covered in the section entitled "Discussion."

The metallographic structure of an isostatically pressed sample that was rolled to $10 \%$ reduction and not homogenized is shown in Figure 20. The light colored delta-phase grains in the figure are surrounded by the darker alpha phase. Note that the $10 \%$ deformation had no significant effect on the microstructure. For comparison, the structure of an isostatically pressed sample that was rolled to $10 \%$ reduction and homogenized for 10 hours at $450{ }^{\circ} \mathrm{C}$ is shown in Figure 21 .

FIGURE 17. As-Cast Structure of a 4- by 4- by 1.125 In. Ingot of Pul-1 Wt \% Fa Alloy. Etched 200X.

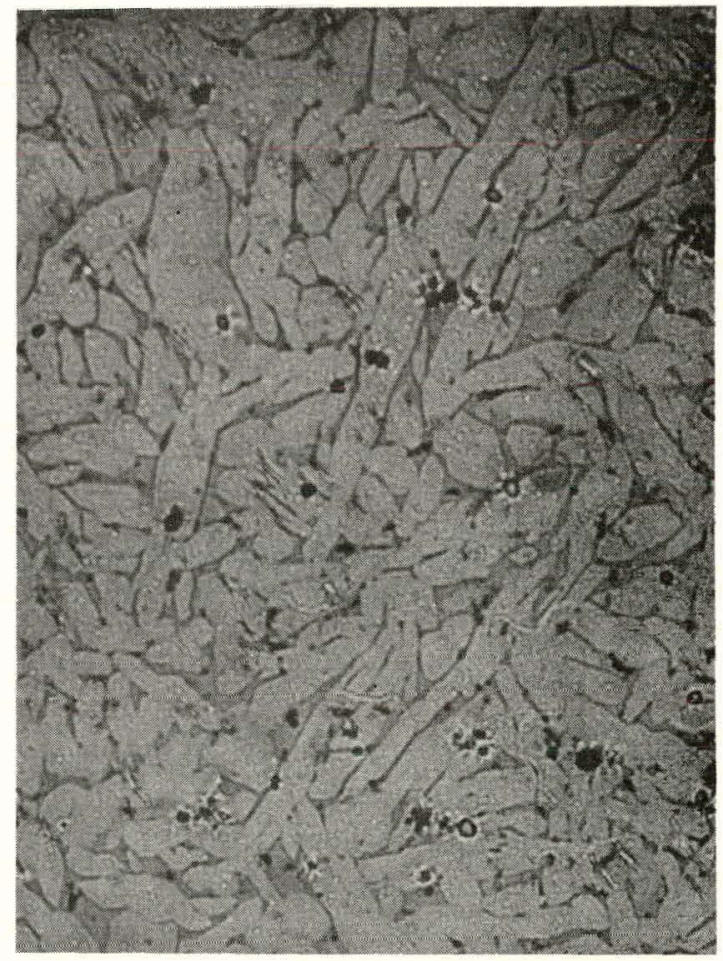


TABLE 3. The Effect of Rolling and Subsequent Isostatic Pressing on the Density of AsCast, Nonhomogenized, Pu-1 Wt \% Ga Alloy.

\begin{tabular}{|c|c|c|}
\hline $\begin{array}{l}\text { Reduction } \\
(\%) \\
\end{array}$ & $\begin{array}{c}\text { As-Rolled Density } \\
\left(\mathrm{g} / \mathrm{cm}^{3}\right)\end{array}$ & $\begin{array}{l}\text { Isostatically Pressed Density } \\
\left(\mathrm{g} / \mathrm{cm}^{3}\right)\end{array}$ \\
\hline 0 & 15.951 & 16.231 \\
\hline 10 & 15.927 & 16.218 \\
\hline 30 & 15.995 & 16.215 \\
\hline 50 & 16.026 & 16.220 \\
\hline 70 & 16.061 & 16.227 \\
\hline 90 & 16.167 & 16.275 \\
\hline
\end{tabular}

FIGURE 18. The Effect of Homogenization Time at $450{ }^{\circ} \mathrm{C}$ on the Isostatically Pressed (30 Minutes at 85,000 psi) Density of Pu-1 Wt \% Ga Alloy.

\section{$\underline{\text { Legend }}$}
- Cast
Homogenized $\rightarrow$ Isos. Pressed
- Cast $\rightarrow$ Rolled 10\% Reduction $\rightarrow$ Homogenized $\rightarrow$ Isos. Pressed
口 Cast $\rightarrow$ Rolled 30\% Reduction $\rightarrow$ Homogenized $\rightarrow$ Isos. Pressed
$\Delta$ Cast $\rightarrow$ Rolled 50\% Reduction $\rightarrow$ Homogenized $\rightarrow$ Isos. Pressed
Cast $\rightarrow$ Rolled $70 \%$ Reduction $\rightarrow$ Homogenized $\rightarrow$ Isos. Pressed
- Cast $\rightarrow$ Rolled 90\% Reduction $\rightarrow$ Ilomogenized $\rightarrow$ Isos. Pressed

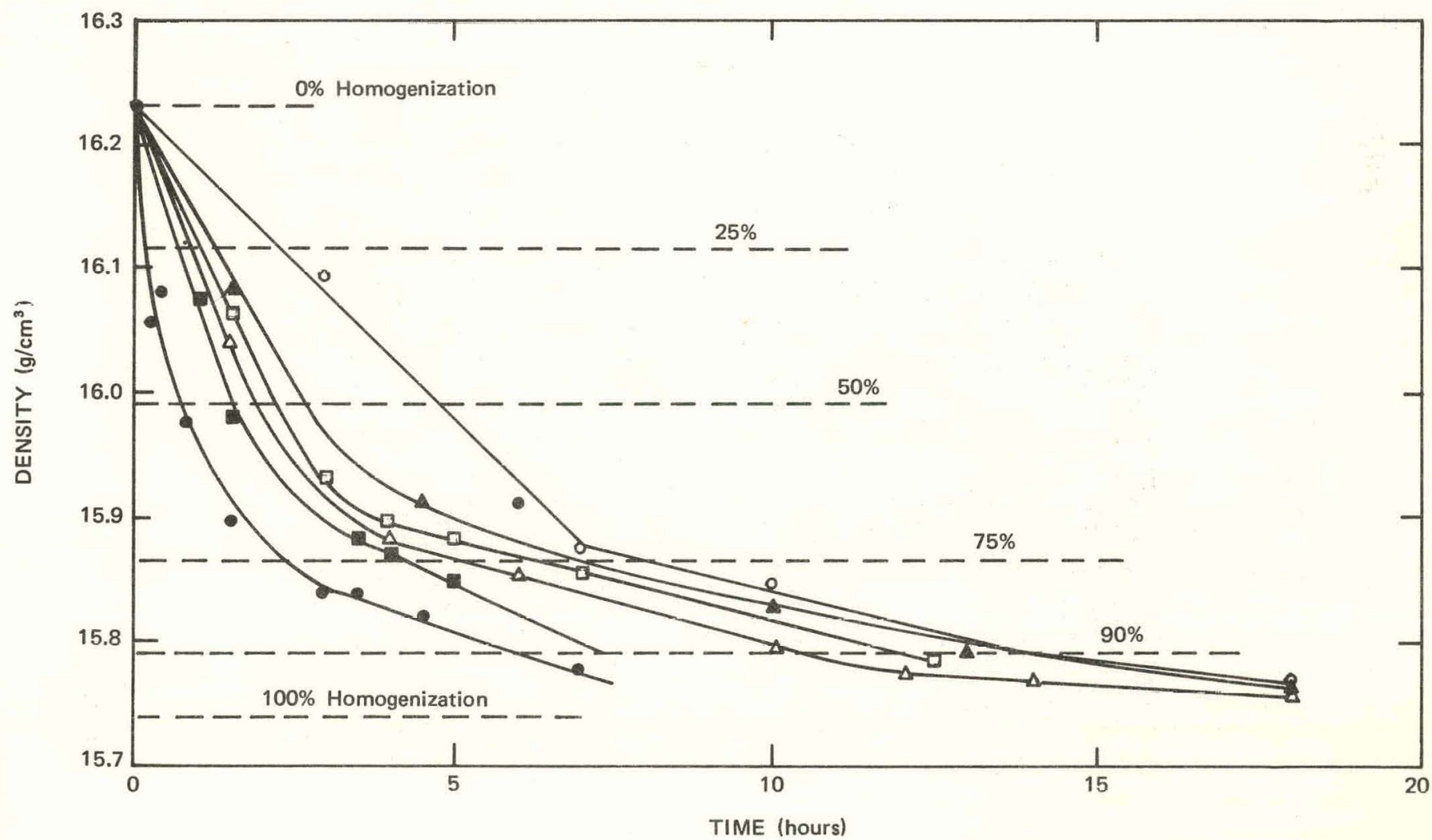



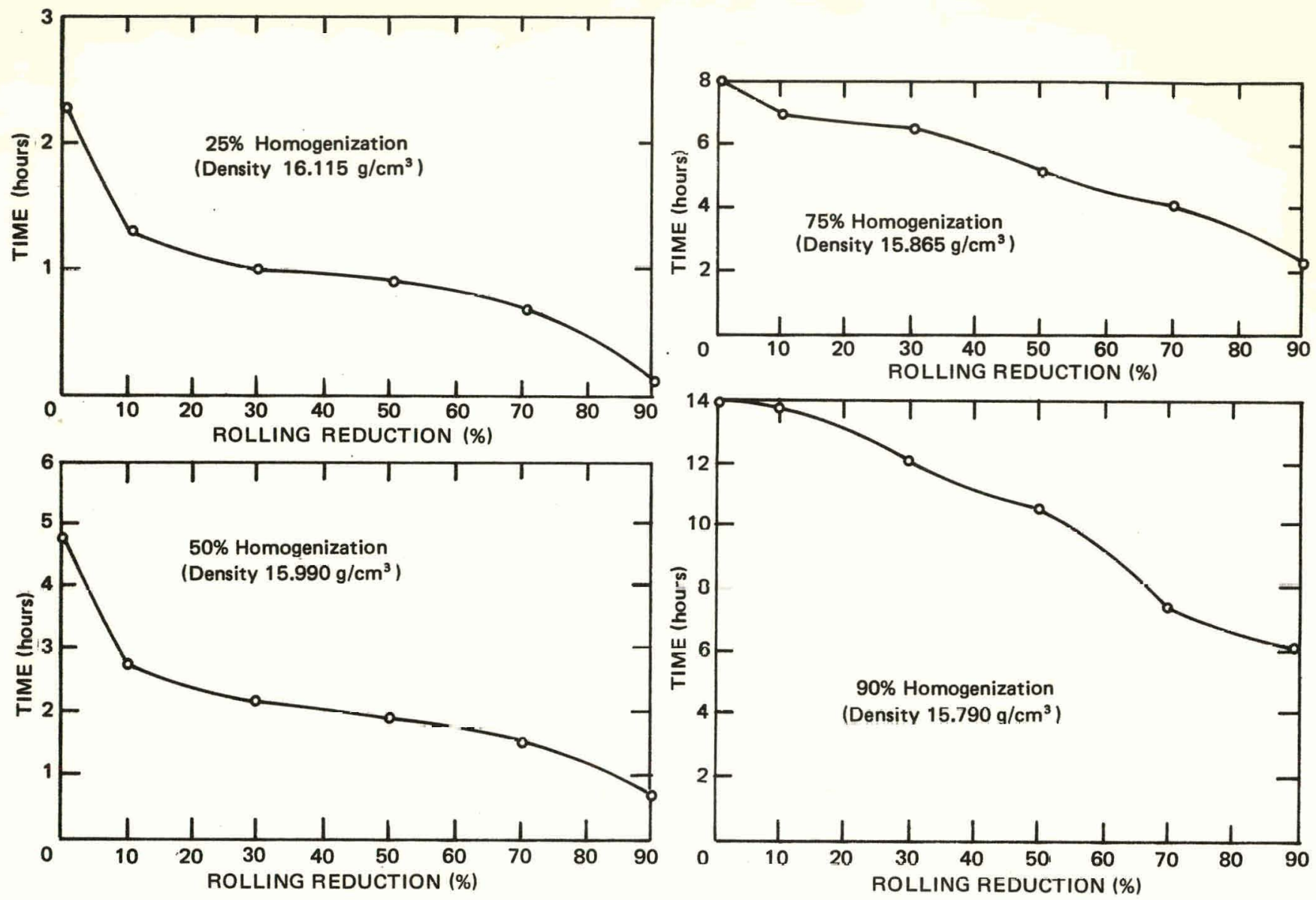

FIGURE 19. Time Required for 25, 50, 75, and $90 \%$ Homogenization as a Function of Percent Reduction by Rolling.

FIGURE 20. Metallographic Structure of Pu-1 Wt \%

Ga Alloy After 10\% Rolling Reduction and Isostatic

Pıessing (30 Minutes at $85,00 \mathrm{U}$ psi). Etched - 200X

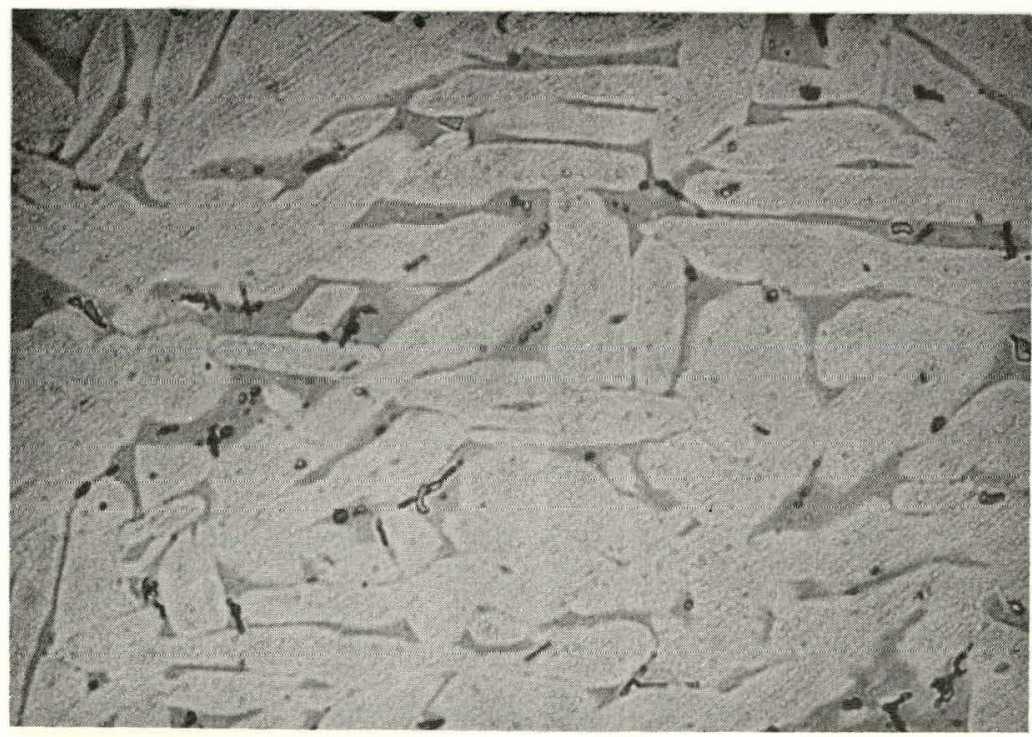




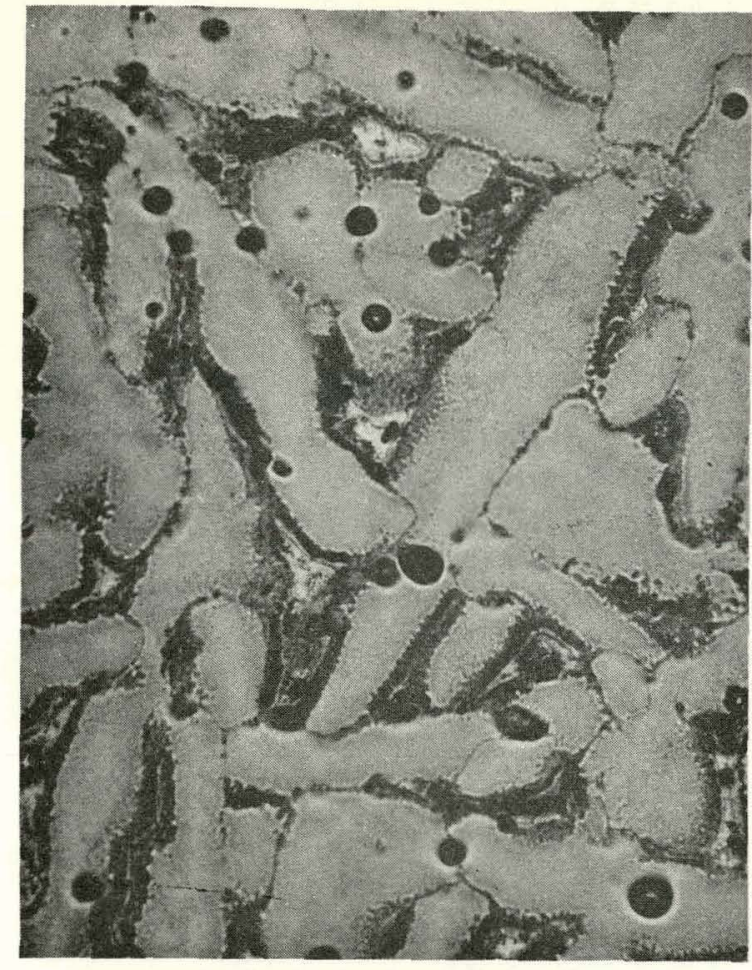

FIGURE 21. Metallographic Structure of Pu-1 Wt \% Ga Alloy After 10\% Rolling Reduction, a 10 -Hour Homogenization at $450{ }^{\circ} \mathrm{C}$, and Isostatic Pressing (30 Minutes at 85,000 psi). The Black Spots Are Etch Pits. Etched - 200X

The homogenized sample had somewhat larger grains as may be expected because of grain growth. Other than some evidence of grain growth, the structure in Figure 21 appears nearly identical to the $10 \%$ as-rolled structure. A similar comparison was made for samples rolled at 50 and $90 \%$ reduction.

The structure of a sample as-rolled to $50 \%$ reduction with no homogenization, Figure 22, may be compared to one rolled to $50 \%$ reduction and homogenized for 3 hours at $450^{\circ} \mathrm{C}$, Figure 23 . Note in Figure 22 the deformed structure with the light colored delta-phase grain cores surrounded by the darker alpha phase in the grain boundaries. Note also the equi-axed recrystallized grain structure in Figure 23, and that the etch has stained the regions of low gallium, thereby depicting the remaining partially cored structure. The flowing color contrast is an effect commonly

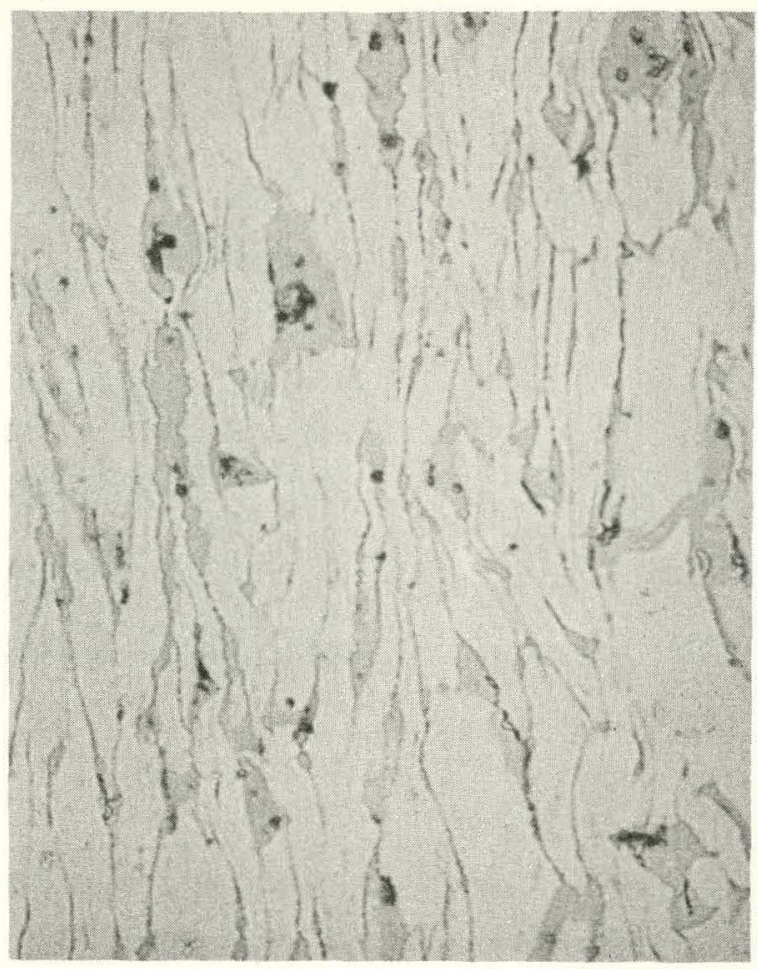

FIGURE 22. Metallographic Structure of Pu-1 Wt \% Ga Alloy After 50\% Rolling Reduction and Isostatic Pressing (30 Minutes at 85,000 psi). Etched - 200X caused by differences in etching characteristics of low versus high gallium composition.

Figure 24, an isostatically pressed sample as-rolled to $90 \%$ reduction, shows localized areas of alpha phase (darker in color). It is theorized that the localized areas are segments of grain boundary alpha phase surrounded by a matrix of light colored deformed delta phase and/or triple points, the interstitual areas between the grains that were the last to solidify, thus containing the least amount of gallium. In Figure 25, an isostatically pressed sample rolled to $90 \%$ reduction and homogenized for 48 minutes at $450{ }^{\circ} \mathrm{C}$, note the equi-axed structure of recrystallized grains. The dark stained areas around the localized alpha phase indicate the areas of low gallium.

In summary, rolling reduces the time required to achieve homogenization of gallium in plutonium; 


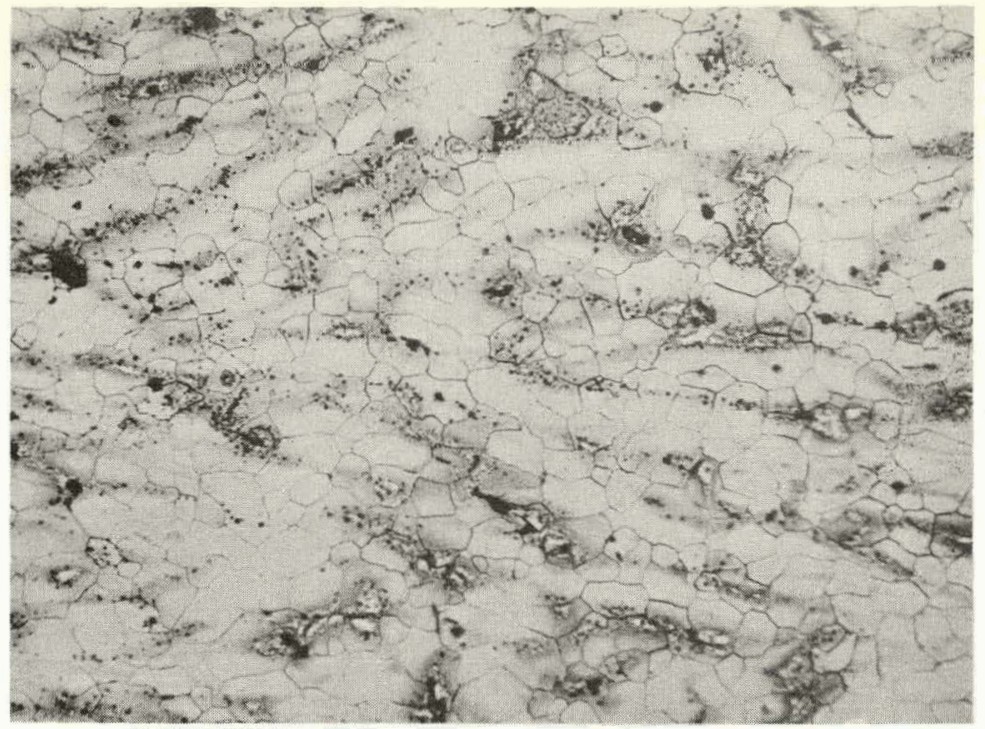

FIGURE 23. Metallographic Structure of $\mathrm{Pu}-1 \mathrm{Wt} \%$ Ga Alloy After 50\% Rolling Reduction, a 3-Hour Homogenization at $450{ }^{\circ} \mathrm{C}$, and Isostatic Pressing (30 Minutes at $85,000 \mathrm{psi}$ ). Etched - 200X

FIGURE 24. Metallographic Structure of Pu-1 Wt \% Ga Alloy After 90\% Rolling Reduction and Isostatic Pressing (30 Minutes at $85,000 \mathrm{psi})$. The Small Black Spots Are Etch Pits. Etched - 200X

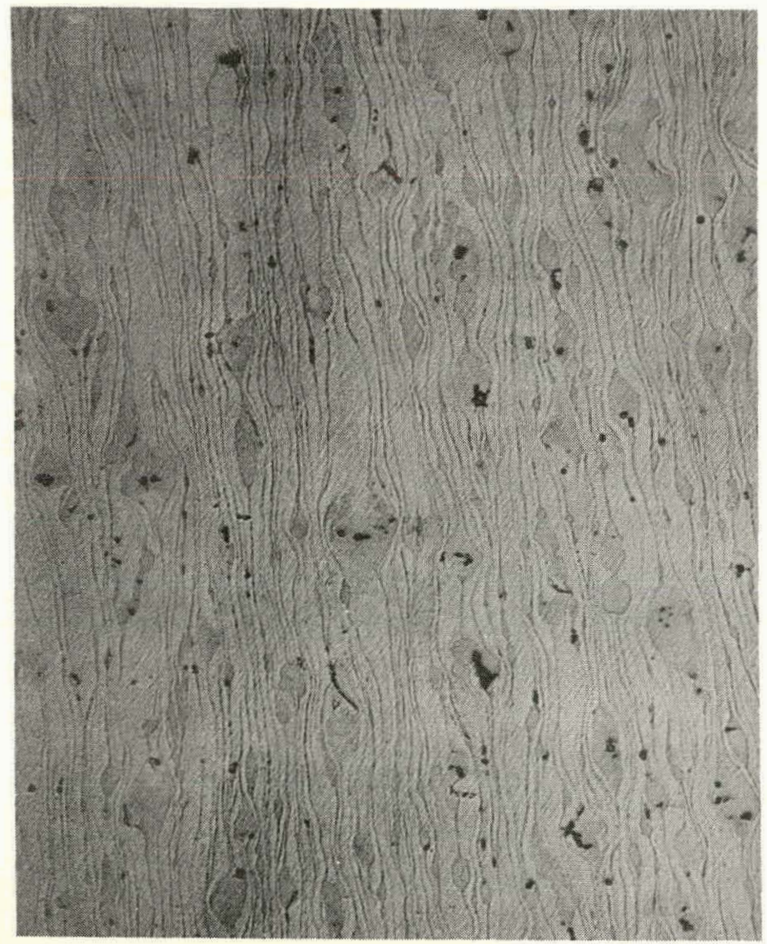

FIGURE 25. Metallographic Structure of Pu-1 Wt \% Ga Alloy After 90\% Rolling Reduction, 48 Minutes Homogenization at $450{ }^{\circ} \mathrm{C}$, and Isostatic Pressing (30 Minutes at $85,000 \mathrm{psi})$. Etched - 200X

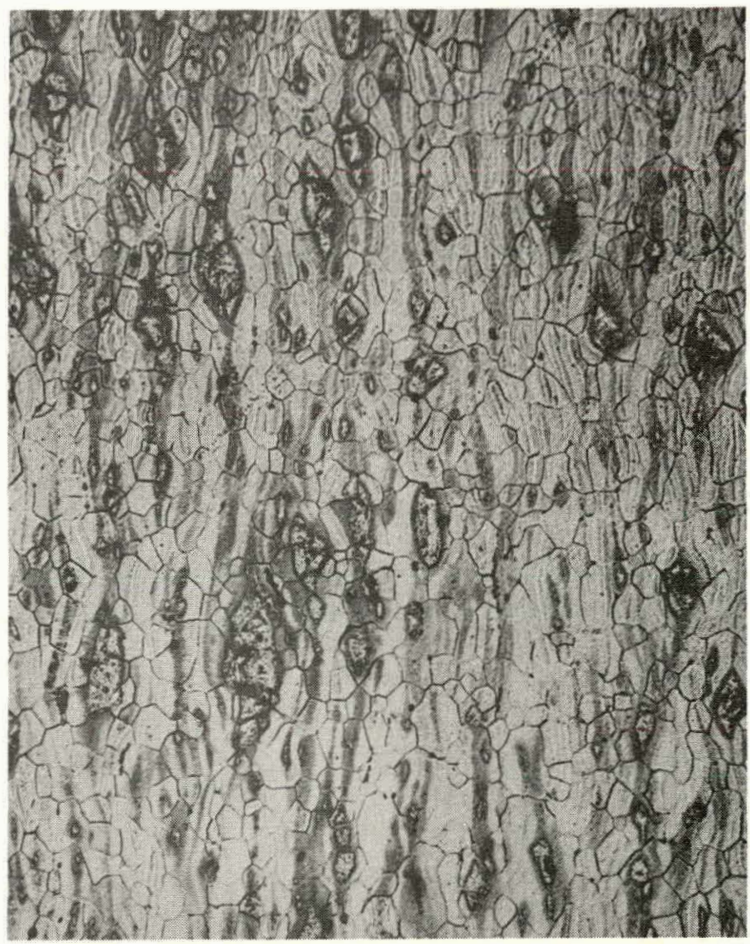


the decrease in annealing time increases with increasing reduction prior to homogenization. The next section explains the mechanism by which rolling reduces the annealing time.

\section{DISCUSSION}

This secton discusses and predicts homogenization of as-cast and rolled samples, and explains results obtained experimentally.

\section{Predictions of Homogenizing Times for As-Cast Samples}

Predicting homogenizing times for the cast samples was accomplished in several steps. First, diffusion models were developed so theoretical galliumconcentration profiles could be calculated. Next, assuming an as-cast cylindrical grain $0.050 \mathrm{~mm}$ in diameter, theoretical-concentration profiles calculated by the diffusion models were compared to an actual concentration profile determined by other investigators. The diffusion models were then used to further predict concentration profiles after homogenization at $450^{\circ} \mathrm{C}$ for various periods of time. The predicted profiles were converted into theoretical densities. A comparison of theoretical and actual curves of density versus homogenization time was made.

\section{Diffusion Models}

Three diffusion models were evaluated as potential means of predicting the homogenization of as-cist Pu-1 wt \% Ga alloy. The three models are introduced as:

\section{$\underline{\text { Sinusoidal }^{12}}$}

$C(x, t)=C_{1}+\left(C_{1}-C_{0}\right) \cos (\pi x / \ell) \exp \left(-D t \pi^{2} / \ell^{2}\right)$

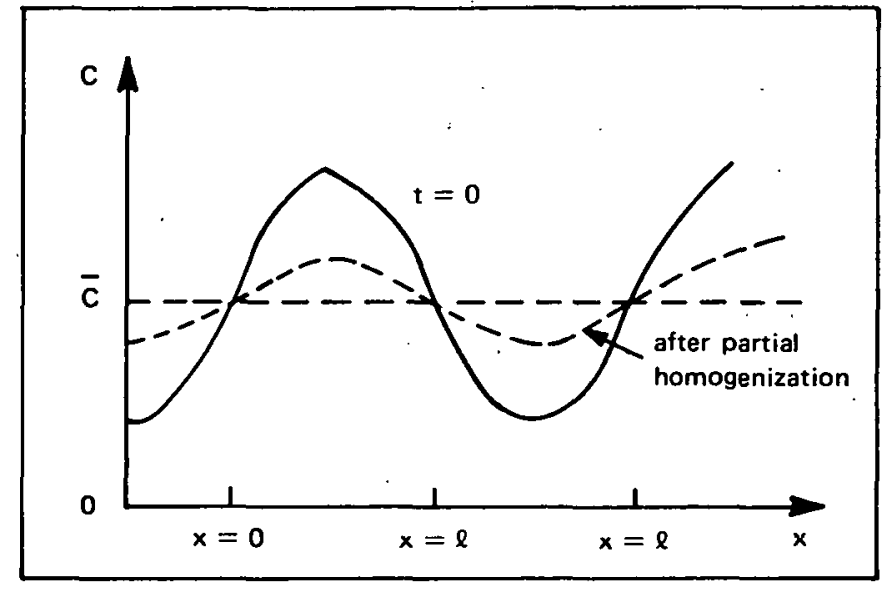

$$
\begin{aligned}
& \mathrm{C}(\mathrm{x}, \mathrm{t})-\begin{array}{l}
\text { Concentration }(\mathrm{wt} \%) \text { at distance } \\
\mathrm{x} \text { from the grain boundary }(\mathrm{x}=0) \\
\text { at time }(\mathrm{t})
\end{array} \\
& \mathrm{C}_{1} \quad-\begin{array}{l}
\text { Nominal Ga concentration of the } \\
\text { alloy }(\mathrm{wt} \%)
\end{array} \\
& \mathrm{C}_{0} \quad-\quad \begin{array}{l}
\text { Minimum Ga concentration in the } \\
\text { grain }(\mathrm{wt} \%)
\end{array} \\
& \ell \quad-\text { Radius of grain }(\mathrm{cm}) \\
& \mathrm{D} \quad-\text { Diffusivity }(\mathrm{cm} / \mathrm{sec})
\end{aligned}
$$

Given a gallium-concentration profile, as described by the equation above, homogenization characteristics of the alloy may be calculated. This analysis accounts for diffusion in only one dimension.

\section{$\underline{\text { Thin Film }}{ }^{14}$}

$$
\mathrm{C}=\frac{a}{2 \sqrt{\pi \mathrm{D} t}} \exp \left(-\mathrm{x}^{2} / 4 \mathrm{Dt}\right)
$$

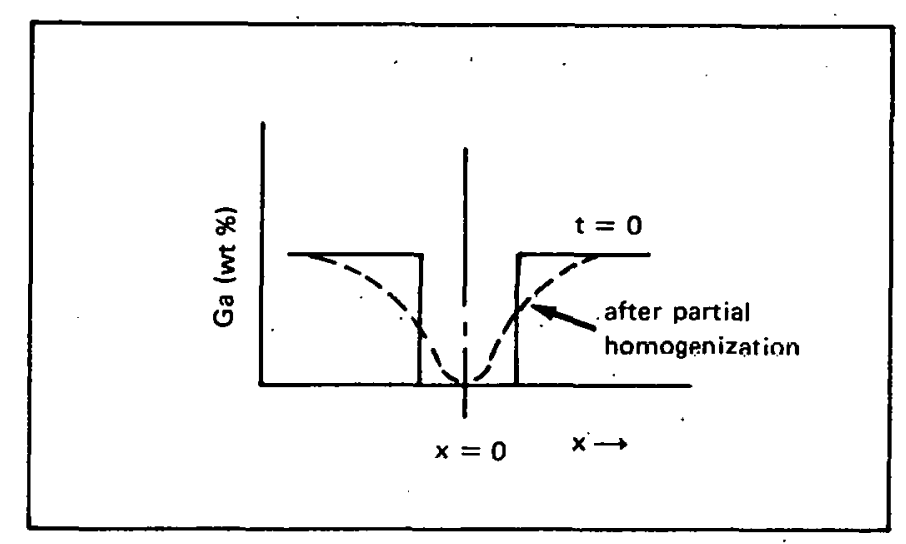


This solution assumes that a thin film (thickness a) of unalloyed plutonium is instantaneously bonded between two infinite rods of Pu-Ga alloy of constant gallium composition. Gallium in the composite rod is then allowed to diffuse until the theoretical gallium profile in the rod simulates the known gallium profile in a cored grain. Using the elapsed time as a baseline, the homogenization response of as-cast grains may be calculated. This solution also assumes one dimensional diffusion.

\section{$\underline{\text { Incremental }}$}

Using a cylindrical model and Fick's First Law of Diffusion, an incremental concentration change may be calculated by the equation

$$
\mathrm{J}=-\mathrm{D} \Delta \mathrm{C} / \Delta \mathrm{x}
$$

if three reference planes within the model are considered as shown in the following:

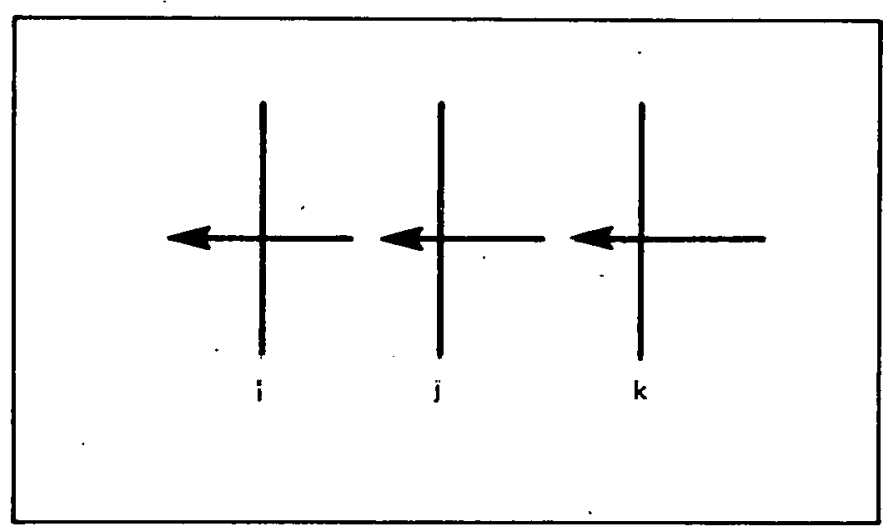

Starting at the grain boundary, the change of concentration at the $j$ plane is given by the equation

$$
\Delta \mathrm{Cj}=-\mathrm{D}(\mathrm{Cj}-\mathrm{Ci}) \frac{\Delta \mathrm{t}}{\Delta \mathrm{x}^{2}}
$$

The general relationship between diffusion time and distance, namely that $x^{2} \sim t$, results from the fact that the concentration gradient and the volume of material into which diffusion is occurring have an $\mathrm{x}$ dependence.
In the grain interior, the change of concentration is given by the equation

$$
\Delta C j=-D\left[(C i-C j) \frac{x j}{x k}-(C j-C k)\right] \frac{\Delta t}{\Delta x^{2}}
$$

At the grain center, the change of concentration is given by the equation

$$
\Delta \mathrm{Cj}=-\mathrm{D}(\mathrm{Ck}-\mathrm{Cj}) \frac{\Delta \mathrm{t}}{\Delta \mathrm{x}^{2}}
$$

This method incorporates the cylindrical geometry and therefore takes into account two-dimensional diffusion (i.e., radially).

Fitting the Initial Gallium Concentration Profile

Attempts were made, using the three diffusion models described, to predict the density response of the as-cast samples as shown in Figure 18. The sinusoidal and thin-tilm methods were fitted to the gallium-concentration profile determined by Ferrera, et al. ${ }^{5}$ for an as-cast, $0.050=\mathrm{mm}$ diameter $\mathrm{Pu}-1 \mathrm{wt} \% \mathrm{Ga}$ alloy grain. The results are shown in Figure 26. Note that the two theoretical curves are in reasonable agreement with the experimental data except that the sinusuidal solution predicts unrealistlc gallium concentrations in the grain center.

\section{Comparing Theoretical and Actual Homogenization}

The thin-film solution was used to calculate galliumconcentration profiles for several homogenization times at $450^{\circ} \mathrm{C}$. Using the calculated concentration profiles and the calibration curve shown in Figure 13, theoretical densities were calculated. The following equation was uscd to incrementally calculate the theoretical density of a grain:

$$
\rho_{\mathrm{T}}=\frac{\begin{array}{c}
\rho_{0} \pi \mathrm{x}_{0}{ }^{2} \mathrm{~h}+\rho_{1} \pi\left(\mathrm{x}_{1}{ }^{2}-\mathrm{x}_{0}{ }^{2}\right) \mathrm{h} \\
+\rho_{2} \pi\left(\mathrm{x}_{2}{ }^{2}-\mathrm{x}_{1}{ }^{2}\right) \mathrm{h}--
\end{array}}{\pi \mathrm{x}^{2} \mathrm{~T}^{\mathrm{h}}}
$$




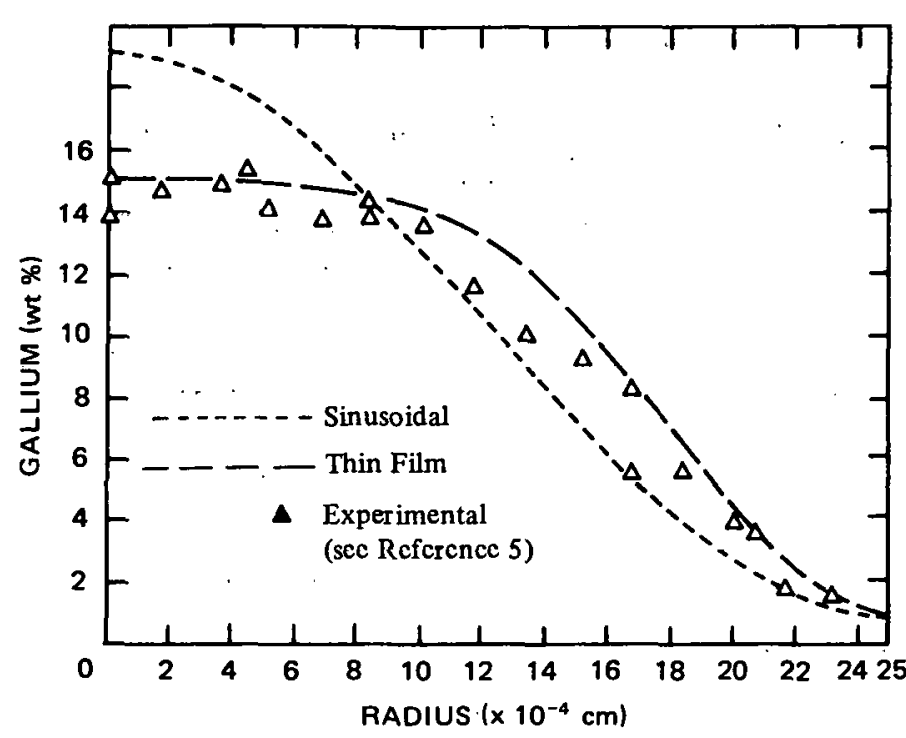

FIGURE 26. A Comparison of the Theoretical and Experimentally Determined Gallium-Concentration Profiles.

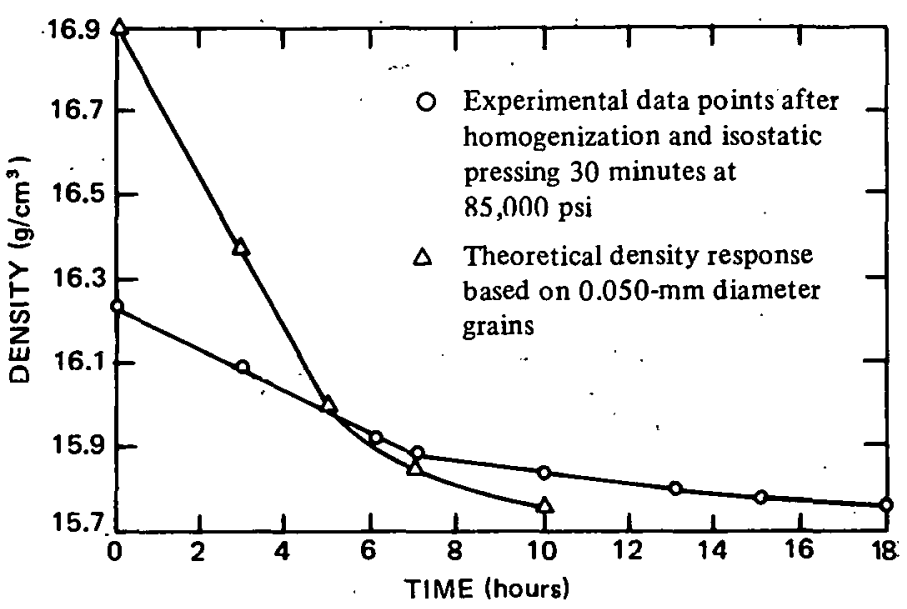

FIGURE 27. The Theoretical "Thin Film" Homogenization of a $0.050-\mathrm{mm}$ Diameter Grain of Pu-1 Wt \% Ga Alloy, Compared to the Actual Homogenization of the Alloy.
A comparison of the thin-film solution and experimental data collected on the cast Pu-1 wt \% Ga alloy samples is shown in Figure 27. Note that the two curves are not in good agreement. The originally cored, theoretical grain density was significantly higher than the experimental density. Based on this difference, it was assumed that the actual gallium concentration profile in the cast structure is not represented by the profile determined by Ferrera, et al. It may also be that . the cylindrical grain model does not adequately describe the system.

A similar set of calculations was completed for the sinusoidal solution. Again, the theoretical calculations did not agree with the experimentally determined results. Several sets of calculations were made using the incremental solution. To minimize accumulative errors inherent in that type calculation, it was determined that extremely small increments of distance and time would have to be used. Since the overall objective of this project was to determine the effect of percent reduction by rolling on homogenization rates, predicting the homogenization rate of the cast alloy was considered of secondary importance.

It was decided that a modified galliumconcentration profile, one that would predict the as-cast density, would be useful. The data obtained by Ferrera, et al., indicated gallium concentrations of $\sim 0.1 \mathrm{wt} \%$ in the grain boundaries. Using that value as the gallium concentration in the grain boundary, the slope of a linear concentration profile was adjusted until the theoretical density agreed with the actual isostatically pressed density $\left(16.23 \mathrm{~g} / \mathrm{cm}^{3}\right)$ of the as-cast alloy. The modified galliumconcentration profile shown in Figure 28 is used later to help explain the effect of rolling on homogenization rates.

In summary, note that poorly defined initial conditions were probably responsible for the lack of agreement between predicted and measured values of homogenization times in the cast samples. The use of one-dimensional diffusion models, while incurring some error, is not altogether inaccurate because most of the diffusion occurred 


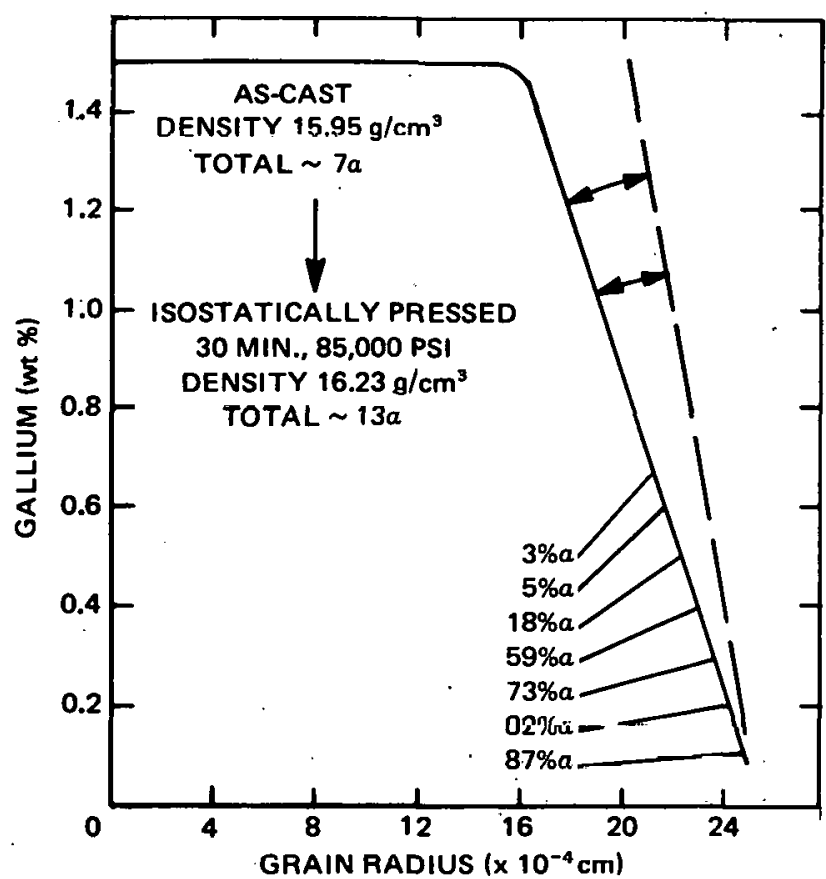

FIGURE 28. A Theoretical Gallium Concentration Profile for the As-Cast Grains of Pu-1 Wt \% Ga Alloy.

near the grain boundary of the cylindrical grains. When the diffusion distance is short, relative to the cylinder radius, diffusion may be effectively described by a one-dimensional model.

\section{Predictions of Homogenization Times for Rolled Samples}

Two assumptions may be made in analyzing the effect of percent reduction on time required for homogenization; namely, that the mechanical properties are uniform across the cored grain or that the mechanical properties are nonuniform. Deformation resulting from both cáses are discussed. The mechanical properties of Pu-Ga alloys were used to predict the deformation of cored Pu-1 wt \% Ga alloy grains. Finally, the theoretically predicted homogenization of rolled samples, based on uniform and nonuniform deformation, was compared to the actual homogenization as determined experimentally.

\section{Uniform Mechanical Properties}

Rolling is known to produce plane strain in rolled sheet. The sheet gets longer and thinner, but not wider. Assuming that, on the average, plane strain exists in rolled grains, the following condition exists:

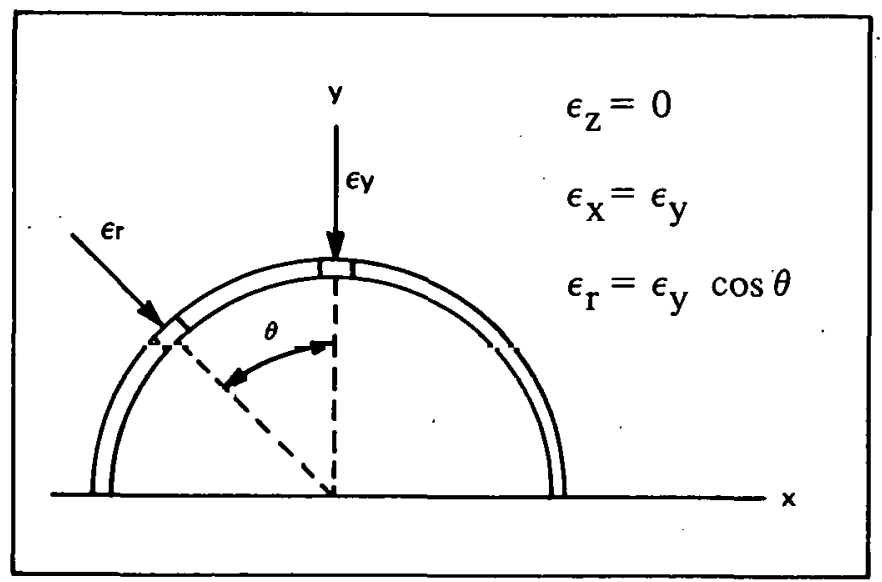

As shown earlier, homogenization time varies with the square of the distance that gallium atoms must be transported, $\left(t \sim x^{2}\right)$. Based on the assumption of uniform mechanical properties, it may be assumed that diffusion distance in a grain varies with the amount that the ingot is rolled (percent reduction, $\mathrm{R}$ ).

$$
\begin{aligned}
& x=x_{0}(1-R) \\
& t=\left[x_{0}\left(1-R^{\prime}\right)\right]^{2} \approx t_{0}(1-R)^{3}
\end{aligned}
$$

This relationship is simplified in that it does not correct for plane-strain considerations. The equation below averages the effect of strain variation across a grain:

$$
\begin{aligned}
& i=\frac{\int_{0} \pi / 2 x_{0}{ }^{2}(1-R \cos \theta)^{2} d \theta}{\int_{0} \pi / 2 d \theta} \\
& i=x^{2}\left(1-\frac{4 R}{\pi}+\frac{R^{2}}{2}\right)
\end{aligned}
$$




\section{Nonuniform Mechanical Properties}

It is expected that the gallium variations across a cored grain will be accompanied by mechanical property variations. This should result in localized deformation across the grain and hence will affect the rate of homogenization. Localized deformation may affect the homogenization of the grain in several ways depending on what portion of the grain is deformed. Consider a grain of two separate regions. The overall deformation of the grain is based on the accumulative deformation of both regions ( $x R=x_{1} R_{1}+x_{2} R_{2}$ ). If one region, say Area 1, accommodates all deformation, then the deformation in that region may be expressed by the following relationship:

$$
\mathrm{R}_{2}=\mathrm{O} ; \quad \mathrm{R}_{1}=\frac{\mathrm{xR}}{\mathrm{x}_{1}}=\mathrm{KR}
$$

where

$$
\mathrm{K}=\begin{aligned}
& \text { constant of nonuniformity } \\
& \text { deformation }
\end{aligned}
$$

For the purpose of homogenization, the critical diffusion zone is the rcgion with $<0.7 \mathrm{wt} \% \mathrm{Ga}$. The regions below $0.7 \mathrm{wt} \% \mathrm{Ga}$ are not stable to isostatic pressing and require gallium diffusion to become stable. If localized deformation occurs, it may be that the high gallium $>0.7 \mathrm{wt} \%$ ) region accepts all the deformation or that the low gallium region $(<0.7 \mathrm{wt} \%)$ accepts all the deformation. The effects of deformation in the two regions on the homogenization time are discussed.

The mechanical properties of $\mathrm{Pu}-\mathrm{Ga}$ alloys are reviewed and used to predict the type deformation of an as-cast grain of $\mathrm{Pu}-1$ wt $\% \mathrm{Ga}$ alloy.

\section{Deformation of the High Gallium Region}

If the deformation within a grain occurs in the high gallium region, the concentration gradient outside the critical diffusion zone will be increased. The effect of a change of concentration gradient on the homogenization time may be expressed by the equation $t=\left[x_{0}(1-R)\right]$.
With localized deformation, the equation becomes $t=\left[x_{0}(1-K R)\right]$. That relationship, as corrected for plane strain considerations, is

$$
\begin{aligned}
& \overline{\mathrm{t}}=\frac{\int_{0} \pi / 2 \mathrm{x}_{0}(1-K R \cos \theta) \mathrm{d} \theta}{\int_{0} \pi / 2 \mathrm{~d} \theta} \\
& \overline{\mathrm{t}}=\mathrm{x}_{0}\left(1-\mathrm{KR} \frac{2}{\pi}\right)
\end{aligned}
$$

This indicates a linear dependence of homogenization time and percent reduction.

\section{Deformation of the Low Gallium Region}

If the deformation within a grain occurs in the low gallium region, the result would be an increase of concentration gradient and a decrease of diffusion zone thickness. The relationship between homogenization time and percent reduction is shown as

$$
t=\left[x_{0}(1-K R)\right]^{2}
$$

That relationship, corrected for plane strain considerations, is

$$
\begin{aligned}
& \bar{t}=\frac{\int_{0}^{\pi / 2} \mathrm{x}_{0}{ }^{2}[1-K R \cos \theta]^{2} \mathrm{~d} \theta}{\int_{0} \pi / 2} \mathrm{~d} \theta \\
& \overline{\mathrm{t}}=\mathrm{x}_{0}{ }^{2}\left(1-\frac{4}{\pi} \mathrm{KR}+\frac{\mathrm{K}^{2} \mathrm{R}^{2}}{2}\right)
\end{aligned}
$$

\section{Deformation of the Cored Pu-1 wt \% Ga Alloy Grains}

It is known that the mechanical properties of $\mathrm{Pu}-\mathrm{Ga}$ alloys vary, as a result of solution hardening, with percent gallium. ${ }^{15}$ The tensile yield strength of plutonium as a function of weight percent 
TABLE 4. A Summary of the Compressive and Tensile Room-Temperature Properties of Unalloyed and Gallium Alloyed Plutonium.

TENSILE PROPERTIES

Pu-1 wt \% Ga (As-Rolled)

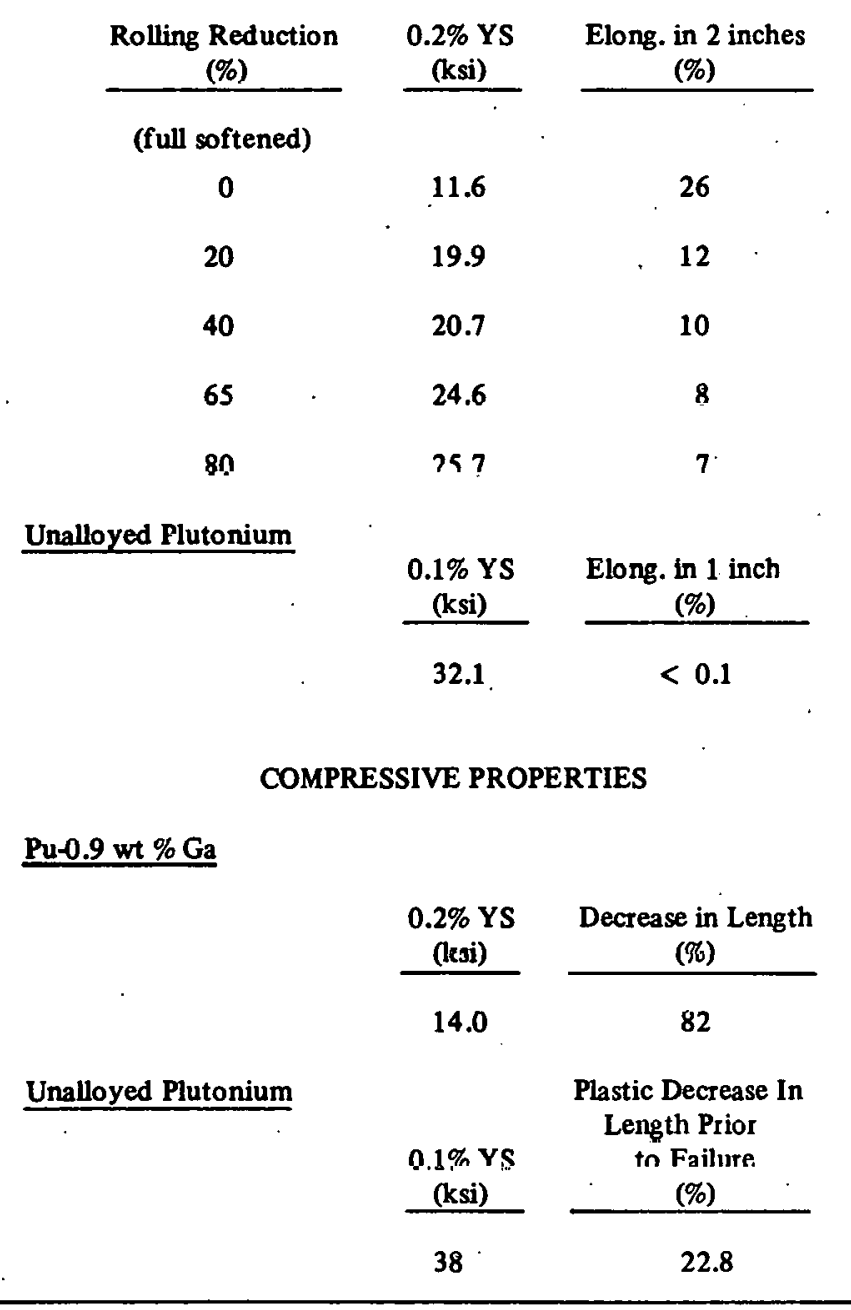

gallium is shown in Figure 29.15 In addition, the mechanical properties of $\mathrm{Pu}-1 \mathrm{wt} \% \mathrm{Ga}$ (as-rolled), ${ }^{16}$ Pu-0.9 wt \% Ga, ${ }^{4}$ and unalloyed plutonium ${ }^{\mathrm{i} \overline{7}}$ are compared in Table 4. Based on the mechanical properties, it is expected that as-cast grains of Pu-1 wt \% Ga alloy will deform nonuniformly when rolled.

The schematic diagram shown in Figure 30 depicts the predicted behavior of a cored grain when an

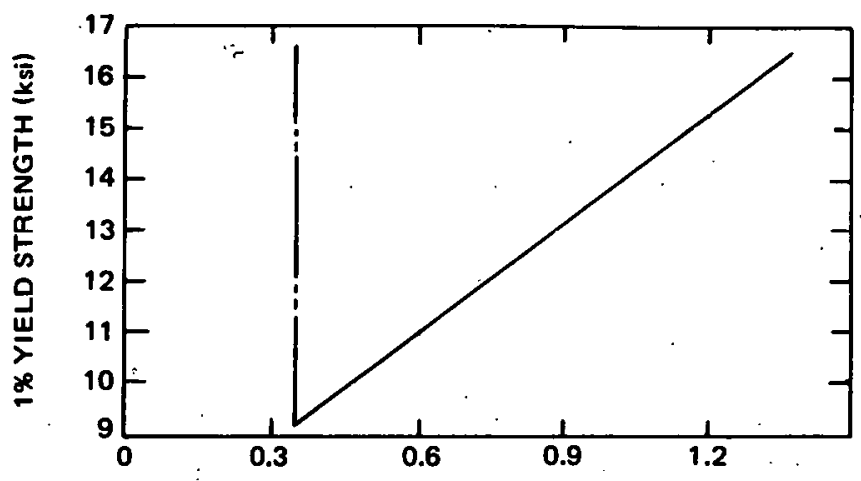

GALLIUM (wt \%)

FIGURE 29. The $1 \%$ Tensile Yield Strength of Plutonium as a Function of Percent Gallium.

ingot is roilied to $10 \%$ reduiction. The diagram is developed from the theoretical-gallium profile. shown in Figure 28. In the diagram, three areas of different mechanical properties are categorized.

Area 1 is the core of the grain and is estimated to contain essentially all $1.5 \mathrm{wt} \%$ gallium. The average tensile yield strength of Area 1 is estimated as $17.5 \mathrm{ksi}$.

Area 2 has gallium ranging from 0.35 to $1.5 \mathrm{wt} \%$. Kcop in mind that the portions of the grain below $0.7 \mathrm{wt} \%$ gallium will have to be brought up to that concentration before the grain will be completely stable to 85,000 psi isostatic pressure. Area 2 has an estimated average yield strength of $13.3 \mathrm{ksi}$.

Arca 3 contains gallium from 0.1 to $0.35 \mathrm{wt} \%$, has the largest percent of alpha phase, and thus is the strongest with an estimated average yield strength of $25 \mathrm{ksi}$.

Based on the mechanical property differences between the three areas, it is assumed that, initially, Area 2 will accommodate essentially all deformation within the grain. The localized percent reduction in Area $2\left(R_{2}\right)$ may be calculated as follows: 

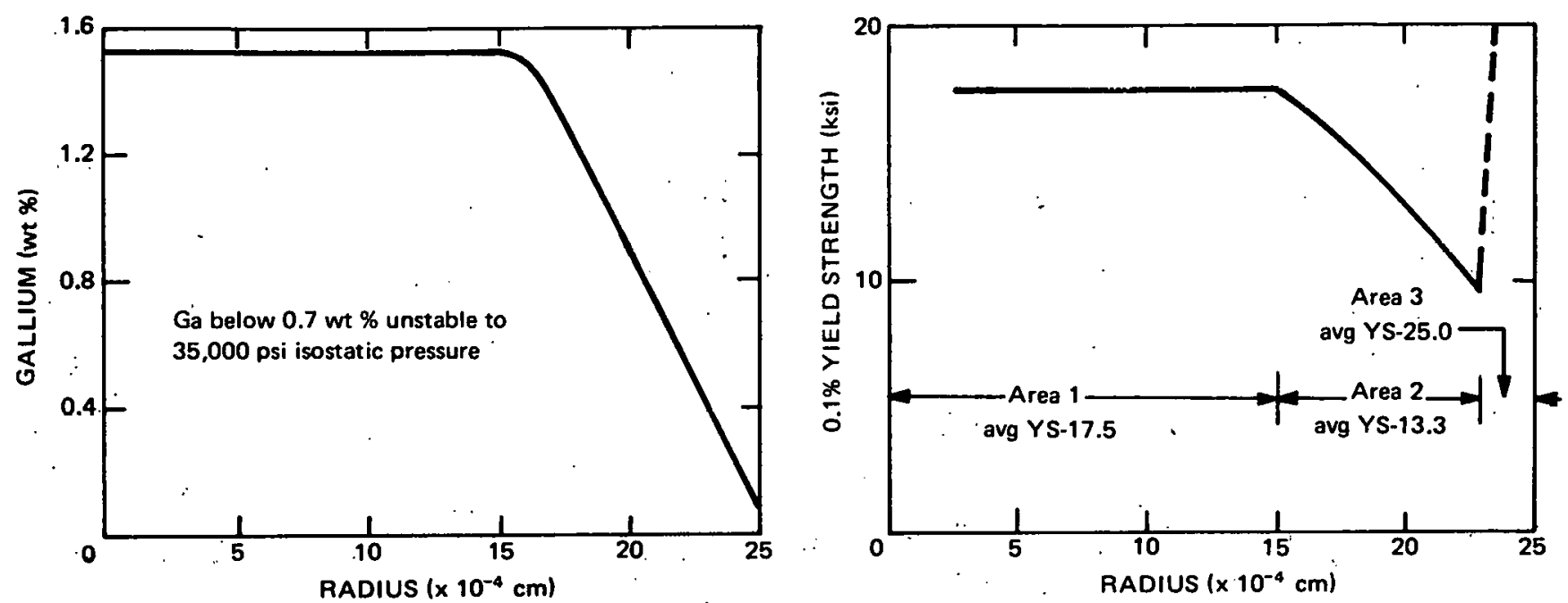

ROLLED $10 \%$
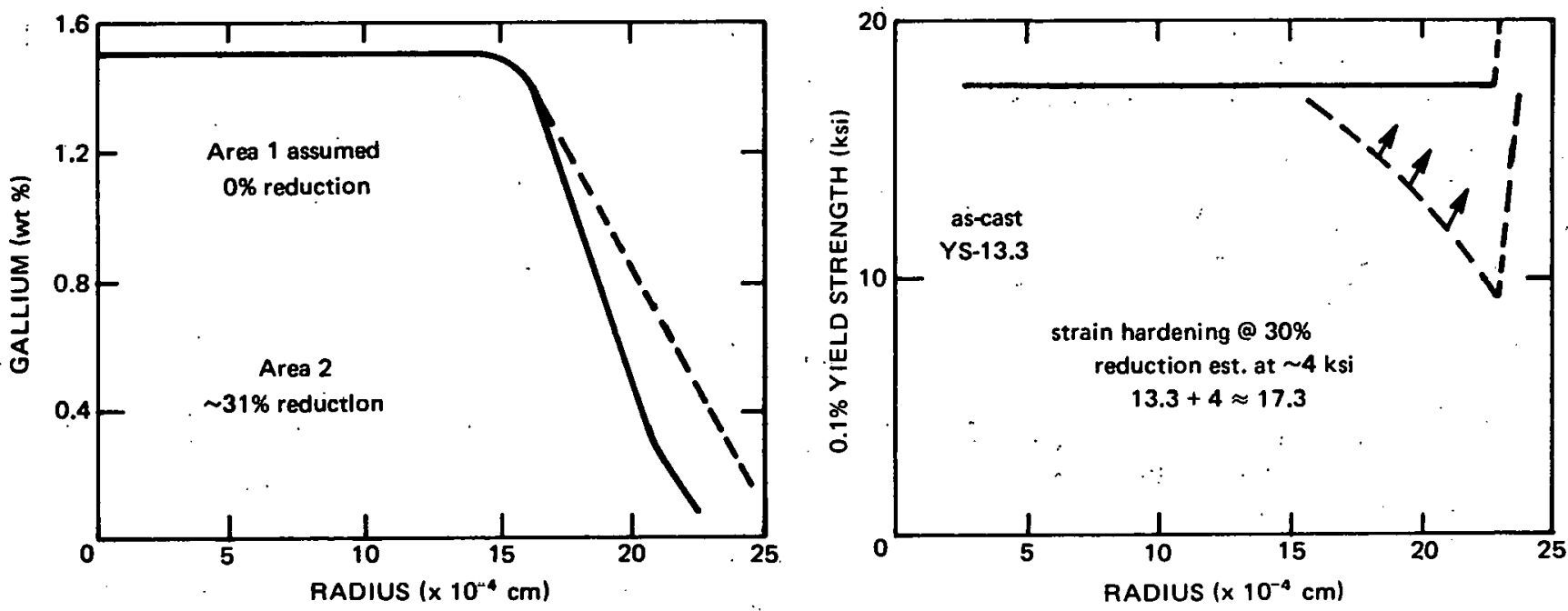

FIGURE 30. A Schematic Diagram Depicting Nonuniform Mechanical Properties within a Grain, Predicted Localized Deformation, and the Resultant Localized Strain Hardening.

$R_{2}=\left(\frac{x}{x_{2}}\right) R=K R$ if $x=0.025 \mathrm{~mm}$

$\mathrm{K}=3.1$, and $\mathrm{x}_{2}=0.008 \mathrm{~mm}$

$\mathrm{R}_{\mathbf{2}}=3.1 \mathrm{R}$

If the grain is deformed $10 \%, \mathrm{R}=0.1$, then the localized deformation in Area 2 is $31 \%$. From
Table 4, it may be seen that Pu-1 wt \% Ga alloy, .when rolled to $30 \%$ reduction, strain hardens $\sim 8 \mathrm{ksi}$. Therefore, it is expected that Area 2 will accommodate all deformation in the grain until such time that strain hardening equalizes the mechanical properties of Areas 1 and 2. At that time, the grain deformation will be accommodated by Areas 1 and 2. Based on the data presented in Table 4, it may be expected 

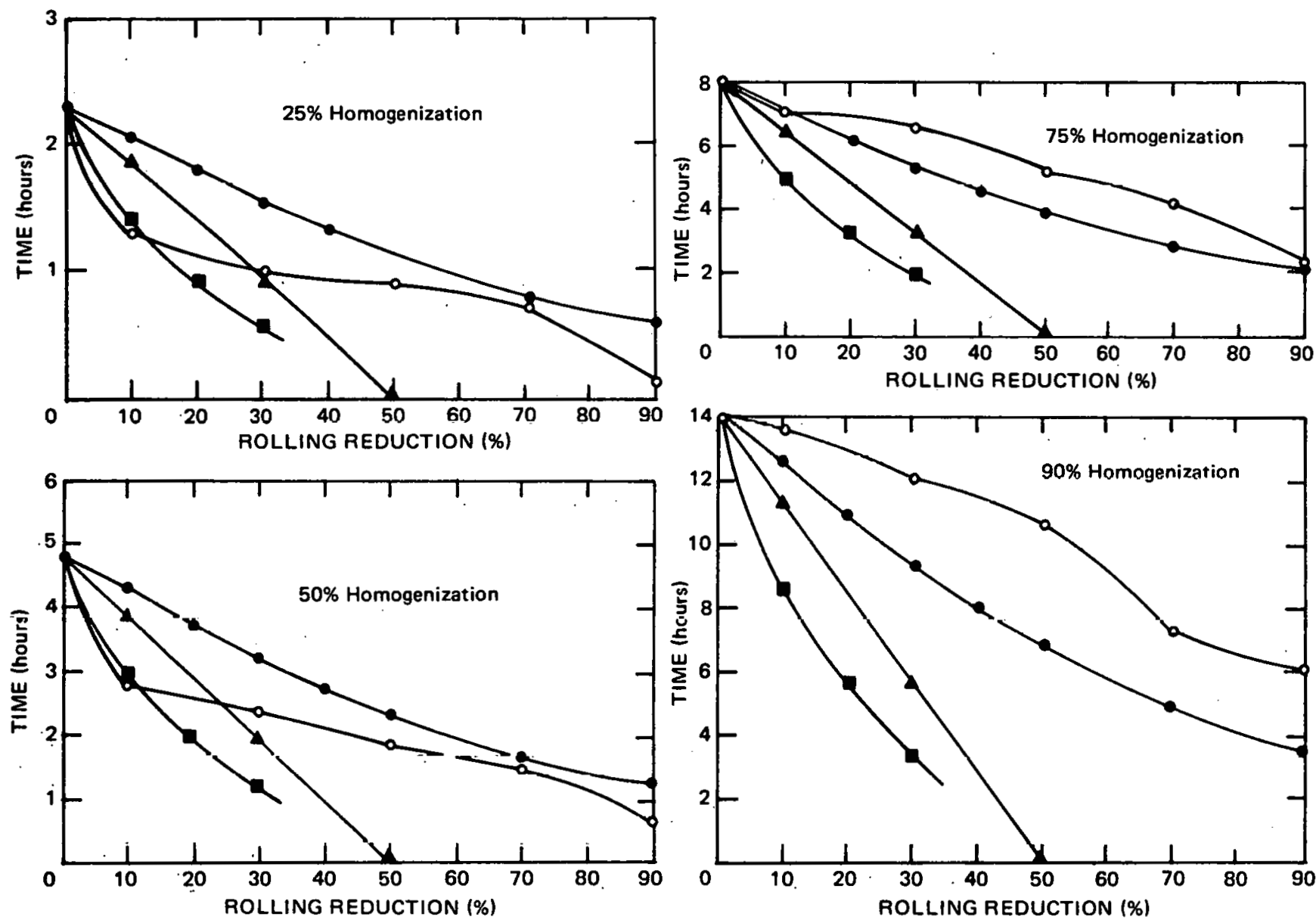

Legend

- Experimental Data

- Theoretical - Uniform Mechanical Properties

Theoretical - Nonuniform Mechanical Properties -

Deformation of Low Gallium

- Theoretical - Nonuniform Mechanical Properties -

Deformation of High Gallium

FIGURE 31 . The Time Required for $25,50,75$, and $90 \%$ Homogenization as a Function of Pcrcent Reduction by Rolling. Also Plottcd arc the Theoretically Predicted Effects Caused by both Uniform and Nonuniform Mechanical Properties across the Grains of Pu-1 Wt \% Ga Alloy. 
that the mechanical properties of Areas 1 and 2 will equalize by the time the ingot is rolled to $10 \%$ reduction (31\% in Area 2 ).

As shown in Table 4, Pu-1 wt \% Ga alloy strain hardens to $\sim 26 \mathrm{ksi}$ when rolled to $80 \%$ reduction. It is therefore expected that large percent reductions of the ingot will cause strain hardening in Areas 1 and 2, such that portions of Area 3 will deform.

\section{Comparing Theoretical and Actual Homogenization}

Three theoretical relationships of homogenization time as a function of percent reduction were developed by assuming either uniform or nonuniform mechanical properties in a rolled grain. A theoretical constant of nonuniform deformation $\mathrm{K}$ for $\mathrm{Pu}-1$ wt \% Ga alloy was calculated to be 3.1. The three theoretical relationships of homogenization time as a function of percent reduction, applied to $\mathrm{Pu}-1$ wt \% alloy, are superimposed on the experimental data obtained for $25,50,75$, and $90 \%$ homogenization. The results are shown in Figure 31. It appears that the grains are initially deformed nonuniformly, but as larger percent reductions $(>10 \%)$ are attained, the strain hardening across the grain causes essentially uniform deformation. It also appears that the triple points and possibly other regions of low gallium resist deformation enough to be relatively insensitive to percent reduction. This is shown by the curve of $90 \%$ homogenization. This is also verified metallographically in Figure 24 by areas of localized alpha phase in the matrix of rolled delta phase.

\section{CONCLUSIONS}

The following conclusions were reached as a result of this project:

1. The minimum concentration of gallium necessary to stabilize the delta phase of plutonium to $85,000 \mathrm{psi}$ isostatic pressure is 0.7 wt \%.

2. The effect of rolling on homogenization of $\mathrm{Pu}-1 \mathrm{wt} \% \mathrm{Ga}$ alloy is dependent on the degree of homogenization desired. The following conclusions were obtained for partial ( 25 to $50 \%$ ) homogenization:

a. Small rolling reductions $(\leqslant 10 \%)$ cause large increases in the rates of homogenization. This is caused by localized deformation in the as-cast grains. Essentially all deformation is accommodated by the low gallium region of the grain that is adjacent to the low gallium, high strength, grain boundary region.

b. Additional rolling reductions $>10 \%$ to $<70 \%$ ) cause additional increases in the homogenization rate, but less increase per increment of strain compared to the initial $10 \%$ reduction. This is attributed to equalization of the mechanical properties across the grains as a result of strain hardening, and thus, more uniform deformation.

c. Large rolling reductions $(>70 \%)$ cause the rate of homogenization to increase. This is attributed to strain hardening across the delta-phase region of the grain such that the higher strength grain boundary region accommodates some of the overall grain deformation.

3. The following conclusions were obtained for near complete $(90 \%)$ homogenization:

a. The rate of homogenization is relatively insensitive to rolling reductions, as compared to the effect of rolling on partial homogenization. This is attributed to the resistance of high strength, low gallium areas, such as triple points and grain boundary regions, to deformation during rolling. 


\section{REFERENCES}

1. W. N. Miner and F. W. Schonfeld. "Physical Properties." Plutonium Handbook, Gordon and Breach, Science Publishers, New York, 1967, Pages 31-59.

2. F. H. Ellinger, C. C. Land, and V. O. Struebing. "The Plutonium-Gallium System." Journal of Nuclear Materials 12:226-236. 1964.

3. K. A. Johnson. Homogenization of GalliumStabilized Delta-Phase Plutonium. LA-2989. Los Alamos Scientific Laboratory, University of California, Los Alamos, New Mexico. Fébruary 28, 1964.

4. H. R. Gardner. Physical and Mechanical Metallurgy Studies on Delta-Stabilized Plutonium-Gallium Alloys. BNWL-13. Battelle-Northwest Laboratory, Richland, Washington. April, 1965.

5. D. W. Ferrera, J. H. Doyle, and M. R. Harvey. Gallium Coring Profiles for Plutonium-1 Weight Percent Gallium Alloys. RFP-1800. Rocky Flats Division, Dow Chemical U.S.A. May 11,1972 .

6. M. R. Harvey, J. H. Doyle, A. L. Rafalski, and D. H. Riefenberg. "Chemical Diffusivities of Plutonium-Gallium Alloys in the Epsilon (bcc) Phase,"' Journal of Less Common Metals 23:446-450. 1971.

7. A. L. Rafalski, M. R. Harvey, and D. H. Riefenberg. "Gallium Diffusion in Delta Stabilized Pu-Ga Alloys." American Society for Metals Transactions Quarterly 60:721. 1967.

8. R. J. Jackson, R. J. Pinkney, and R. R. McDonald. "Measurement of Percent Alpha in Delta Stabilized Plutonium Alloys by X-Ray Techniques." Proceedings of Twentieth Metallographic Conference. Denver, Colorado. June, 1966. Page 168.

9. P. G. Hambling, B. R. Spicer, and J. S. White. "The Effect of Uniaxial Compression upon the Transformation of Metastable Delta-Phase Plutonium." Journal of Nuclear Materials 17:172. 1965.

10. R. A. Knight, B. R. Spicer, B. J. Ward, and J. S. White. "Alpha Precipitation in Delta Phase Plutonium." Journal of Nuclear Materials 24:223. 1967.

11. B. R. Spicer and J. S. White. "The Effect of Thermal Cycling upon the Transformation Behavior of Metastable Delta-Phase Plutonium." Journal of Nuclear Materials 22:269-275. 1967.

12. P. G. Shewmon. "Diffusion." Physical Metallurgy. Edited by R. W. Cahn. American Elsevier Publishing Company, Incorporated, New York. 1970. Page 388.

13. P. G. Shewman. "Diffusion in Solids." McGraw-Hill Series in Materials Science and Engineering. 1963. Page 7.

14. S. T. Konobeevsky. "Equilibrium Diagrams of Certain Systems un Pluturiunn Bases." Session on the Peaceful Uses of Atomic Energy. Academy of Sciences, U.S.S.R. Proceedings of the Division of Chemical Sciences III:362-374. Academy of Sciences of the U.S.S.R., Moscow. 1955.

15. D. C. Miller and J. S. White. "The Tensile Properties of Plutonium-Gallium Alloys in the Temperature Range $20-100^{\circ} \mathrm{C}$." Journal of Nuclear Materials 17:54-59. 1965.

16. S. Beitscher. "Annealing of Cold Rolled Pu-1 wt \% Ga Alloy." Journal of Nuclear Materials 45:1-9. 1972/73.

17. H. R. Gardner and I. B. Mann. "Mechanical Property and Formability Studies on Unalloyed Plutonium." Plutonium 1960. Cleaver-Hume Press Ltd., London. 1961. Pages 513-570. 